\title{
Chinese social capital in a business context: The impact of business ethics, business etiquette and business orientation on relationship building and performance
}

Kim-Shyan Fam

School of Management

Harbin University of Commerce

Kang'an Road, Daoli,

Harbin, China

Email:kimfam@mcfamuniversity.com

Djavlonbek Kadirov*

Wellington School of Business and Government

Victoria University of Wellington

Wellington, New Zealand

Email: djavlonbek.kadirov@vuw.ac.nz

*Corresponding author

\author{
Ahmet Bardakc1 \\ Department of Business \\ Faculty of Economics and Administrative Sciences \\ Pamukkale University \\ Denizli, Turkey \\ Email: abardakci@pau.edu.tr
}

Davor Vuchkovski

Faculty of Economics

University of Ljubljana

Ljubljana, Slovenia

Email: davor.vuchkovski@ef.uni-lj.si

James E. Richard

Wellington School of Business and Government

Victoria University of Wellington

Wellington, New Zealand

Email: james.richard@,vuw.ac.nz 


\section{Biographical notes:}

Kim-Shyan Fam is Chair Professor in Marketing at Harbin University of Commerce, Founding Director of MAGScholar, and the Founding Editor of Asian Journal of Business Research (SCOPUS) and Journal of Halal Service Research. His fields of research and publications include cross-cultural marketing communication, marketing channels, and relationship marketing. Currently he is leading an international research team to explore the importance of business ethics and etiquette on relationship performance across a business lifecycle.

Djavlonbek Kadirov ( $\mathrm{PhD}$ ) is Senior Lecturer in Marketing at Wellington School of Business and Government, Victoria University of Wellington, New Zealand. Djavlonbek's research interests include marketing systems, market formation and development, and market-related moral issues. His research has appeared in Journal of Macromarketing, Journal of Marketing Management, Journal of Business Research, Journal of Brand Management, Consumption Markets \& Culture, and Journal of Islamic Marketing.

Ahmet Bardakc1 (PhD) is Professor of Marketing at the Department of Business, the University of Pamukkale, Turkey. He holds MSc and PhD in Marketing from the University of Salford (UK) where he was involved in research on mass customization. His research interests mainly include international marketing and strategic marketing.

Davor Vuchkovski, PhD candidate and Lecturer in international business, School of Economics and Business, University of Ljubljana, Slovenia. Research interests: international business in emerging markets (with a focus on India), catch up of emerging market service providers, business in Central and Eastern Europe.

James E Richard (PhD) is Associate Professor in Marketing at the School of Marketing and International Business, Victoria University of Wellington, New Zealand. His teaching and research interests include Customer Relationship Marketing, Internet marketing, and Mobile marketing, including investigating marketing issues with respect to cross-cultural business ethics and etiquette, information disclosure and risk, the impact of digitalisation, and social media on SME brand management. He is an associate editor for Journal of Research in Interactive Marketing, and Electronic Markets, as well as an Editorial Review Board member for the European Journal of Marketing, and the Journal of Marketing Analytics.

Abstract: This research explores the extent business ethics and etiquette influence relationship performance across the business relationship lifecycle. Based on a survey from 583 business people from several major Chinese business hubs, this research finds that business ethics and etiquette significantly influence relationship performance success. Dimensions of business ethics such as relationship fairness and relationship stability are found to be significantly associated with relationship performance at the growth and maintenance stages, respectively. Commitment/loyalty business etiquette protocols are found to be important at all stages of the 
business relationship lifecycle. Additionally, the study found that goal-oriented males and females are more likely to use business ethics and etiquette in comparison to apathy-driven males and females to build successful relationship performance.

\section{INTRODUCTION}

Cultural differences between China and the West have been found to impact business partnerships and relations. This has been subject of many studies from managerial and consumer focal point (Ding, Vuchkovski, Žabkar, Hirose, \& Rašković, 2018; Littrell, Alon, \& Wai Chan, 2012). While some research goes even beyond the understanding of China as a monolith and explore regional differences the focus of our study is the importance of business ethics and etiquette in a business relationship lifecycle in a quanxi based environment (Littrell et al., 2012). This study contributes to the relational marketing and management literature by investigating business practices from a cultural ethics and etiquette perspective (Brettel et al., 2012; Murphy et al., 2007).

Ethical business values, real and perceived, are critical dimensions to an organisation's culture and decision making. The growth of multi-national business and real-time communications contribute to cultural protocol mistakes and misunderstandings in the global economy (Singhapakdi, Marta, Rao, \& Cicic, 2001). Research indicates that common ethical values and morals are important in building long term business relationships with suppliers, partners and customers (Singhapakdi, Kraft, Vitell, \& Rallapalli, 1995). Similarly, business etiquette protocols and manners are also important dimensions used in developing and maintaining close business relationships. Sparks and Pan (2010) claim that ethical perspective influences judgement and behaviour in decision-making. However, much of the recent research considers ethical judgement a dependent variable, few if any studies have focused on the alignment and influence of ethics on business relationship building and maintenance (O'Fallon \& Butterfield, 2005). Bejou, Ennew, and Palmer (1998) in their study on customer relationships with financial advisors, found that the ethical behaviour of financial advisor had no significant effect on relationship satisfaction. Murphy, Laczniak, and Wood (2007) propose a relationship marketing conceptual model incorporating ethical values. They suggest that relationship marketing not only requires trust and commitment, but also integrity, fairness, respect and empathy; aspects of ethical virtues. Burnaz, Atakan, Topcu, and Singhapakdi (2009) found that American businesspeople have a higher level of ethical awareness, and give more importance to ethics compared to Turkish, and Thai businesspeople.

This study addresses the call for more cross-cultural focused organizational and management research. Brettel et al. (2012) found that leadership mechanisms in new product development firms are not 'universal' in nature but are influenced by national culture. The authors call for cross-cultural management research focused on national culture as a key independent factor, rather than simply continue stating 'culture matters' (p. 669).

In China, quanxi not only drives the nature of micro-level business relationships, but also it impacts structural changes at the economy level. Some researchers argued that China is moving toward "network capitalism" that is different to market capitalism (Lovett, Simmons, \& Kali, 
1999). Some scholars argue that quanxi is about securing special treatment from people in power, thereby perceiving quanxi as a form of corruption, favouritism and cronyism (Fan, 2002; Kadirov, Varey, \& Wolfenden, 2016). However, such accounts miss the broader view of business relationships in China. Some analysts, taking a Western perspective, assume quanxi represents the antithesis of ethics, while Chinese consider quanxi-related practices to be positively ethical (N. L. Chan \& Guillet, 2011; R. Y. K. Chan, Cheng, \& Szeto, 2002). Chan, Cheng and Szeto's (2002) research attempted to enlighten foreign investors in the Chinese way of doing business by examining trust and commitment in business relationships. However, the impact of broader ethic and etiquette dimensions of conducting business in China and the impact on relationship performance across a business lifecycle remains open. In addition, there is a need to better understand the role gender may play in business relationship development due to the nature of interpersonal relations in China, the high female labour force participation, and female under-representation in executive positions. Bu and Roy (2005, p. 381) state that "...we continue to lack an understanding of such work-related social networking practices in the Chinese context. We know very little about how the composition of and social exchange practices within these networks differ between male and female Chinese managers".

The objective of this study is to consider and better understand the effect of business ethics and etiquette across the business life-cycle in China. The study provides practical advice to business people doing business in China and offers a number of suggestions to increase an organizations' awareness of the influence of business ethics and etiquette in relationship decision making and practice.

The current research focuses on better understanding: a) to what extent business ethics and etiquette influence relationship performance across a business lifecycle? and b) to what extent does gender and business orientation influence the use of business ethics and etiquette to build successful relationship performance in a quanxi-based environment?

\section{LITERATURE REVIEW}

\section{Business Ethics}

Business ethics refers to business organizations' principles, values and norms that influence the behaviour and practices of managers, employees and other individuals within these business organizations (Crane, Matten, Glozer, \& Spence, 2019; Stead, Worrell, \& Stead, 1990). The issues of "right" versus "wrong" in business-related situations and circumstance are at the heart of business ethics (Crane et al., 2019). Business ethics is grounded in day-to-day practices of business professionals and managers (Painter-Morland, 2008). Such practices are largely localized, based on dynamic circumstances, and driven by cultural perceptions. In general, business ethics in China are multi-dimensional involving value tensions such as self-interest versus communitarianism, morality versus materialism, attitudes towards misbehaviour, and atheism versus religiousness (Sardy, Munoz, Jianmin Sun, \& Alon, 2010). Another tension related to business ethics is that of the role of a strongman/leader versus the rule of law reflecting distinct systems of "renzhi" in the North of China and "fazhi" in the South respectively (Rawwas, Wang, Zhao, \& Javed, 2018; Warner \& Zhu, 2018). Yin and Quazi (2018) 
recent review of research on business ethics in the greater China region revealed the following important aspects: corporate social responsibility and social performance, ethical values in decision-making, workplace ethics and practices, marketing and consumer ethics and sustainability.

Distinct from the normative approach on ethics (Dunfee \& Warren, 2001; Laczniak \& Murphy, 2019), in this study we focus on the positive aspects of business ethics in China inspired by Hunt-Vitell's theory of marketing ethics (Hunt, 2019). The issues of justice, fairness, and continuity dominate the discussion of ethics (Oyedijo, Yang, Hicks, \& Dong, 2018). Relationship fairness refers to the concern and care about maintenance of equity in relationships. It involves concerns about equal opportunities and fairness in all outcomes. Justice, fairness, and equity perceptions play an important role not only in competitive clientsupplier relationships (Choi \& Messinger, 2016; Ho, Su, \& Wu, 2014; Qiu, 2018), but also within localized marketing systems (Kadirov, 2018; Kadirov \& Varey, 2011). Relationship fairness is seen as a main component of trust (Michell, Reast, \& Lynch, 1998), since previous research indicates that respect for fairness leads to greater trust between parties (Anderson \& Weitz, 1989). Specifically, at the early stages of a business relationship, relationship fairness is essential since it signals long-term intentions of involved parties (Rempel, Holmes, \& Zanna, 1985).

Researchers distinguish between distributive fairness, procedural fairness, and interactional fairness (Gilliland, 1993; Oyedijo et al., 2018). Y. Liu, Huang, Luo, and Zhao (2012) offer a different classification which comprises the following types of fairness: distributive, procedural, interpersonal, and informational. T.-Y. Kim and Leung (2007) show that the perceptions of fairness in China are largely related to distributive justice, while other types of fairness are also important. Distinct from the distributive and procedural fairness, interactional fairness involves perceptions of equity in social interactions (Oyedijo et al., 2018). This type of fairness is underscored by feelings that parties within exchange relationships must share challenges, difficulties, and problems directly arising from the effort to maintain these relationships. In addition, research indicates that relationship fairness involves the use of the same intellectual criteria when evaluating both own and others' behaviour (Thomson, 1999). Relationship fairness people tend to use the same "yardstick" when evaluating their own action versus the business partner's behaviour. Fair business policies, just procedures, lack of double-standards in asymmetric relationships are a good indication of relationship fairness (Qiu, 2018). The concepts of "fairness" and "equity" have culturally distinct meanings in China (Lovett et al., 1999). Differing from Eurocentric conceptions, as Hui and Graen (1997) argue, fairness in China is linked to the performance and fulfilment of unique roles in broader social networks. It is argued that as individuals become part of broader social networks, equity is increasingly defined in the light of quanxi responsibilities (Leung \& Wong, 2001). Consequently, it can be said that fairness perceptions in China are largely defined by the intensity of quanxi perceptions.

Relationship stability, on the other hand, signifies values underlying the emphasis of commitment in business relationships, promise-keeping, and maintenance of credibility. Ensuring continuity in business relationships is linked to perceptions of relationship quality (Jiang, Shiu, Henneberg, \& Naude, 2016). Interpersonal relationships determine continuity 
which in turn guarantees relationship stability (Anderson \& Weitz, 1989). Consistent change in business networks may create undesirable volatility in business relationships (Fonfara, Ratajczak-Mrozek, \& Leszczyński, 2018), whereas some companies may prefer stability in terms of consistent and invariant relationships with suppliers or clients. Interpersonal relationships that are based on mutual support, trust, commitment over a long-term ensure relationship stability (Akrout, Diallo, Akrout, \& Chandon, 2016; Lawler, 2001). Within quanxi driven social interactions, relation stability is promoted via a complex net of mutual favours (Wang, Siu, \& Barnes, 2008).

\section{Business Etiquette}

Business etiquette refers to culturally informed protocol, manners, rules of conduct and a shared code of behaviour in business relationships within a particular locality (Deale \& Lee, 2019). The knowledge of business etiquette is part of "soft skills" that are key to working with employees, clients, business partners and other stakeholders (Weber, Finley, Crawford, \& Rivera, 2009). Business etiquette not only includes expected manners and acceptable behaviour, but also principles that guide such behaviour (e.g. politeness, consideration). The knowledge of local etiquette is a key factor when doing business in China (Ambler, Witzel, \& Xi, 2017; De Mente, 2016; Leung \& Barnes, 2019; Seligman, 2008). For example, Bader, Froese, Achteresch, and Behrens (2017) suggest that home country culture may be the basis for outgroup categorisation of expatriate employees.

In Chinese society, social relation etiquette pertains to shared socio-cultural protocols based on intricate knowledge of behavioural rites, rules and codes of saving/valuing face, offering and receiving gifts, serving food, maintaining social status differences, using education/personal titles, and developing personal relations. Businesspeople in China who are actively involved in building social relations employ several etiquette approaches, including offering and receiving gifts (Brunner, Chen, Sun, \& Zhou, 1990). Gift giving, at the right time and the right circumstances, is an etiquette skill that Chinese consider to be important in relationship building (R. Y. K. Chan et al., 2002; Lovett et al., 1999). In addition, mianzi (face maintenance) etiquette is strongly intertwined with status-based relationships and reciprocal exchanges ( $\mathrm{Su}$ \& Littlefield, 2001). Reciprocity is often regarded as an important deed for building a strong business relationship.

Commitment etiquette requires a person to follow a code of conduct that symbolizes trust, commitment, loyalty, and relationship confidence. It involves acting within a relationship in a way that personal loyalty, confidentiality and harmony is expressed in doings, sayings, and manners. Appropriate etiquette displaying loyalty is part of moral code in China (Leung \& Barnes, 2019). In addition, the broad spectrum of business etiquette includes oral etiquette. In China, oral etiquette requires skilful communication that involves a delicate combination of verbal and non-verbal communication. Straight talk is not always welcome in such circumstances. Contextualized politeness is a kind of unwritten code which requires avoiding outright requests and demands (Lovett et al., 1999). Just like in complex cultural rituals and rites, business relationships, especially negotiations, are based on interpersonal interactions both formal and informal; hard selling, pressure tactics, or deal closure are less effective, since Chinese prefer ongoing negotiations (Ghauri \& Fang, 2001). According to Graham and Lam 
(2003), in high-level negotiations, it is the peripheral matters of etiquette (e.g., respectful talk, formal address) that decide the outcome of negotiations. Another element of business relationship etiquette is cultural sensitivity etiquette. It is expected that business partners act to emphasize their appreciation of apparent cultural differences. This requires cultural adaptability that is reflected in momentary choices of etiquette. Doing business "right" in China requires not only the knowledge of social practices, customs, and manners, but also an attitude to learn. Chinese businesspeople are aware that some of their cultural practices are perceived as corrupt or unacceptable by Western observers (Guo, Rammal, Benson, Zhu, \& Dowling, 2018; Steidlmeier, 1999). Chinese business people tend to perceive themselves as more culturally competent because they understand, appreciate, and successfully interact with people from different belief systems (Steidlmeier, 1999). Au and Wong (2000) claim cultural competence is largely reflected in the implementation of contracts. Cultural sensitivity requires in-depth knowledge of local customs. For example, one must know that gift giving may not be seen as an equitable reciprocal exchange of favours. Lovett et al. (1999) claim attempting to repay an equal amount (i.e., a purely rational response) might lead to the termination of quanxi relationships.

\section{Quanxi}

Quanxi is a cultural aura that defines the character of business relationships in China (Bian, 2017, 2018, 2019; Guo et al., 2018; Opper, Nee, \& Holm, 2017). It is seen as a form of social capital as well as a strategic capability of building relationships (Opper et al., 2017). Meaningful relationships between individuals which may include both informal and formal networking are the building blocks of quanxi (Chung, 2019; Chung \& Kuo, 2018). Quanxi represents localized networks of adaptive and fluid relationships based on socio-economic interdependence (Bian, 2019; Wong, 1998). These networks represent "a highly differentiated intricate system of overt or covert, as well as formal and informal social subsets governed by an unwritten law of reciprocity" (Wilpert \& Scharpf, 1990, p. 647). Nearly every business undertaking in China requires quanxi (Bian, 2019; Gold, Guthrie, \& Wank, 2002; Guo et al., 2018). Quanxi networks are grounded on a quanxi base, which represents role-based relationships (Brunner et al., 1990; Jacobs, 1982). Quanxi is based on distinct protocols of mutuality and reciprocity (Chen \& Chen, 2004; H. W.-c. Yeung, 2008). Fan (2002) argues that quanxi is a continuous process with the clear demarcation of its beginning and the end. It is activated when a problem (e.g., a businessperson needs assistance) arises, involves people acting as facilitators and intermediaries within social networks, and persists until the problem is resolved. For example, P.-Y. Li et al. (2018) found that strong local connections, gained preferential business treatment and improved firm innovation leading to business success. Quanxi can have a positive lasting impact on both personal and business performance (Hwang et al., 2009; Qian, Yang, \& Li, 2016). Understanding quanxi requires in-depth cultural understanding of business relationships at a local level.

\section{Stages of Business Relationship}

Fam and Waller (2008) identified four clearly distinguished stages of business relationships: inception, growth, maintenance, and dissolution (Y. Liu et al., 2012). Trust and honesty were found to play an important role during the development and maintenance stages, whereas 
closeness and bonding played a significant role at the dissolution stage (Fam \& Waller, 2008). Quanxi's impact on relationship performance during different business relationships phases may strongly vary among individuals (Y. Liu et al., 2012; Oyedijo et al., 2018). I. Yeung and Tung (1996) corroborated the importance of quanxi at the initial stages of forming business relationships, while its importance diminishes as relationships enter the maturity stage. Differing from their Western counterparts, Chinese business people tend to invest more time and effort at the inception stage to develop "renji hexie" (i.e., interpersonal harmony and warm feelings) (Graham \& Lam, 2003). Furthermore, in the inception and growth stages, business partners can be seen as "loosely coupled" where they maintain a degree of independence while gradually increasing the extent of interdependence and mutuality (Y. Liu et al., 2012). The perception of fairness in such circumstances significantly influences business relationship performance (Y. Liu et al., 2012). Moreover, knowledge of the appropriate parameters encompassing the "quanxi-game" comes to the forefront during the initial stages and significantly influences the success of business relationships at the inception and growth stages, since knowledge of the "quanxi-game" is critical at these two stages (Su \& Littlefield, 2001). Specifically, at the early stages of a relationship, fairness is essential, because it signals the long-term intention of the partners (Opper et al., 2017).

\section{Gender}

Despite recent government efforts to reduce gender inequality in China, the societal perception of masculinity tends to enforce male dominance (Xu \& Li, 2015). J. Liu (2017) argues that women in China historically had limited opportunity to build quanxi since quanxi is traditionally a male-oriented system, and the Chinese system of "danwei" in the pre-reform era (before 1970s) clearly discriminated against women in many aspects of life. Notwithstanding recent efforts, women still have less opportunity to cultivate quanxi (J. Liu, 2017; Zhang, 2006). Some researchers argued that females perceive quanxi unfavourably (Yang, 2016). This is because some quanxi tactics are seen incompatible with female gender roles (Xu \& Li, 2015). Quanxi-related gender differences are sharper among people with middle to low social status (McLaren, 2004; Zhang, 2006). Research finds that quanxi is largely applied by men for important projects, while women apply it for relatively small undertakings (Zhang, 2006). Some research shows no gender differences in quanxi practices (Farh, Tsui, Xin, \& Cheng, 1998; Hussain, 2010). Nevertheless, another stream of research shows that women enter business relationships for other purposes than attaining financial gain (Brush, 1992; Longstreth, Stafford, \& Mauldin, 1987). Women harbour intrinsic goals associated with a long-term view and virtue ethics (Rosa, Carter, \& Hamilton, 1996). They emphasize trust, commitment and loyalty as well as social relations (Arnold \& Bianchi, 2001; Ndubisi, 2006).

\section{Business Orientation}

Business orientation refers to the prevailing style or culture of an organisation, such as relationship orientation, entrepreneurial orientation, marketing orientation or production orientation and is considered fundamental for business success (Bennett \& Cooper, 1979; Lynch, Mason, Beresford, \& Found, 2012). The role of business orientation permeates throughout an organisation and influences approaches to business opportunities, guides the company's response to change, and impacts all strategic decisions (H. Liu, Roos, \& Wensley, 
2004; Miles, Crispin, \& Kasouf, 2011).

Chinese business orientation, especially as it relates to the organisation's approach to relationships and risk management may take on a distinctive quanxi perspective (Nee \& Opper, 2010; Robertson, 2000). R. Y. K. Chan et al. (2002) researched Chinese business executives and found that executives who employ quanxi (the authors call them quanxi cultivators) are different to apathetic executives or unethical profit seekers who tend to put less emphasis on quanxi. Quanxi cultivators tend to work in dynamic environments (e.g. private companies and joint ventures). Apathetic executives tend to work in state-owned companies. Competitive environment is more likely to attract executives with high quanxi orientation, while stable business environments are more likely to be associated with apathetic executives (Opper et al., 2017).

\section{HYPOTHESES and METHODOLOGY}

\section{Preliminary study}

A preliminary test was conducted to identify measurable attributes (items) which describe ethics and business etiquette. An initial 54 marketing academics and business individuals from Asia, Middle East, Europe, North America and Oceania completed a survey which asked them to list what they believe are essential ethical behaviours and business etiquette (business manners) in a business relationship in their home country.

Using these results and the results from an extensive literature review (e.g., Burnaz et al., 2009; DesJardins \& McCall, 2014; Ferrell et al., 2015; Marchiori et al., 2014; Murphy et al., 2007; O'Fallon \& Butterfield, 2005; Schaffer \& Kelley, 1993; Shaw et al., 2013; Sparks \& Pan, 2010), a list of 16 ethical attributes and 161 etiquette items were identified.

In a second survey an additional 120 marketing academics and business individuals from Asia, Middle East, Europe, North America and Oceania ranked the relative importance of each item, with the following instructions:

Business ethics are moral principles and behaviours of individuals, including the way in which an organisation conducts its business affairs. With reference to your selected country, please indicate the importance of each of the following characteristics of business ethics in business relationship building ( 1 being most important).

Business etiquette is a set of manners often upheld by custom and enforced by members of a society in order to provide an environment where members feel comfortable and secure in their social and business interactions. With respect to business etiquette please indicate the importance of each attribute in business relationship building in your selected country (1 being most important).

Analysing the survey data for Asia, ten characteristics representing business ethics were identified; commitment to the business relationship, credibility, equity \& equal opportunity, fair competition, fairness (general), governance transparency, keeping promises, reliability, 
social responsibility and similar morals. Using the ranking provided by the respondents (1 being most important), the ranking results were aggregated identifying the most important 25 characteristics of business etiquette;

- Appreciating cultural difference

- Save Face

- Social status consciousness

- Providing suitable expensive gifts

- Commitment to the relationship

- Being competent

- Maintaining confidentiality

- Providing competent solutions

- Maintain harmony

- Valuing 'Face'

- Great host with food

- Gossiping about the client

- Introducing yourself using first name only
- Demonstrate cultural adaptability

- Gift giving is necessary

- Use of education and personal titles

- Mutual trust is key to success

- Mutual confidence

- Demonstrate loyalty

- Meeting commitments

- Respect for all parties

- Developing personal relations

- Straight talking

- Using high pressure sales tactics

- Relationship and business transparency

A subsequent factor analysis identified two dimensions for Business ethics;

- Relationship fairness measured with six items; equity \& equal opportunity, fair competition, fairness (general), governance transparency, social responsibility and similar morals.

- Relationship stability was measured with four items; credibility, commitment to the business relationship, keeping promises, and reliability.

Business etiquette factored into two primary factors, relationship initiation etiquette and relationship quality etiquette, each having two dimensions. The two dimensions of relationship initiation etiquette were;

- Social relation etiquette measured with eight items, and

- Oral etiquette measured with four items.

The two dimensions of relationship quality etiquette were;

- Commitment etiquette measured with eleven items, and

- Cultural sensitivity etiquette measured with two items (See Appendix A).

These results were used to develop the survey used in this study and substantiate the hypotheses.

\section{Hypotheses}

Businesspeople with high levels of quanxi are expected to demonstrate a more pronounced effect of business ethics (based on relationship fairness) on relationship performance at the inception and growth stages. Businesspeople are expected to project themselves as honest and committed to the relationship. In contrast, relationship stability-based business ethics are essential during the maintenance and dissolution stages. Credibility and reliability are very critical during maintenance and dissolution, because these qualities signal trustworthiness 
(Bews \& Rossouw, 2002).

H1a: Quanxi amplifies the effect of relationship fairness on relationship performance at the inception and growth stages.

H1b: Quanxi amplifies the effect of relationship stability on relationship performance at the maintenance and dissolution stages.

Business etiquette linked to business relationship initiation (social relation etiquette and oral etiquette) are critical for enhancing relationship performance during inception and growth. High-quanxi individuals become extremely sensitive to cultural appropriateness, to the extent that basic etiquette mistakes may lead them to abandon potential relationships (Graham \& Lam, 2003). Quanxi involves interactions between individuals rather than firms (Fan, 2002; Leung \& Wong, 2001). In addition, quanxi operates at the tactical social relations level hence social relation etiquette is likely to affect relationship performance (Fan, 2002),. The initial stages of relationship building involve quanxi judgements (I. Yeung \& Tung, 1996), where the episodic manners of developing social relations may drive relationship performance. Specifically, oral etiquette is strongly valued. If businesspeople are highly sensitive to quanxi expectations, they would be more likely to invest in business relationships when their partners exhibit contextualized politeness, avoid hard selling and outright requests, express respect and maintain formality (Ghauri \& Fang, 2001; Graham \& Lam, 2003; Lovett et al., 1999). On the other hand, business etiquettes directed at enhancing relationship quality (e.g., commitment etiquette and cultural sensitivity etiquette) will significantly influence relationship performance during maintenance, and perhaps, dissolution. Commitment and cultural sensitivity etiquettes play an important role when the goal is to maintain a stable relationship. In addition, a person should be culturally competent in quanxi protocols when a relationship is mature and/or in the process of dissolution.

H1c: Quanxi amplifies the effect of relationship initiation etiquette (social relation etiquette and oral etiquette) on relationship performance at the inception and growth stages.

H1d: Quanxi amplifies the effect of relationship quality etiquette (commitment etiquette and cultural sensitivity etiquette) on relationship performance at the maintenance and dissolution stages.

\section{Business Orientation}

The extent of reliance on quanxi gives rise to different managerial approaches (Opper et al., 2017). This research distinguishes between two types of business orientation: goal-focus and apathy. Goal-focus arises as a strategic response to complex and dynamic business environments (Nee \& Opper, 2010), where managers persistently striving towards set objectives. Goal-focus is linked to active implementation of the quanxi principles of transaction-cost economizing and the emphasis of local orthodoxy. It is known that quanxi is associated with long-term risk and uncertainty, hence, risk-averse managers may decide to avoid quanxi (Opper et al., 2017), thus developing a degree of apathy toward quanxi related traditions. Apathetic managers discard the importance of quanxi by assuming that the respect for tradition hampers performance, while gift giving is not necessary.

H2a: For high goal focused managers relationship fairness is positively associated with relationship performance. 
H2b: For high apathetic managers relationship stability is positively associated with relationship performance.

H2c: For high goal focused managers relationship initiation etiquette (social relation etiquette and oral etiquette) are positively associated with relationship performance.

H2d: For high apathetic managers with low quanxi, relationship quality etiquettes (commitment etiquette and cultural sensitivity etiquette) are positively associated with relationship performance.

\section{Gender}

Due to their critical approach to non-ethical aspects of quanxi, women practice quanxi differently than men (Xu \& Li, 2015). Tang's (2019) recent ethnographic study of white-collar workers in Shenzhen, China shows that, although quanxi dynamics are gendered, women are equal quanxi builders in most of the domains studied. Although gender inequality is highly likely in many areas in China, this does not mean that women do not recognize the importance of quanxi (Xu \& Li, 2015). Females are more open to the inclusion of the opposite gender when developing quanxi networks, particularly by well educated, highly career oriented Chinese women, (Bu \& Roy, 2005). Taking the above discussion into account, we believe that

H3a: Females have stronger business ethics (relationship fairness and relationship stability) orientation compared to males during all stages of a business relationship.

H3b: Females have stronger business etiquette (social relation etiquette, commitment etiquette, oral etiquette and cultural sensitivity etiquette) orientation compared to males during all stages of a business relationship.

\section{Quanxi Archetypes}

We combine gender and business orientation to create four business relationship archetypes of quanxi (see Figure1). This exercise results in the following archetypes: goal-focused males, goal-focused females, apathetic males, and apathetic females.

$$
>>\text { Figure } 1 \text { about here }<<
$$

Specific effects can be observed combining business orientation and gender. Males can exhibit less preference for quanxi-based ethics and etiquette in general (H3), however, it would be different when business orientation is taken into account. Goal-focused males would be expected to be effective users of quanxi in comparison to apathetic females. The same difference should hold when goal-focused males are compared to apathetic males.

H4a: For goal-focused males (in comparison to apathetic males and females), business ethics and business etiquettes are positively associated with relationship performance.

On the other hand, goal-focused females would be expected to be effective users of quanxi in comparison to apathetic males and females. Research indicates that young female entrepreneurs greatly benefit from quanxi in attaining business success (Scott, Harrison, Hussain, \& Millman, 2014), while this is unlikely to happen for males who discount the importance of quanxi. Not all females are confident users of quanxi, however, when they figure out socially acceptable ways of exploiting it, then they are likely to be more successful compared to males with no quanxi approach (Scott et al., 2014). 
H4b: For goal-focused females (in comparison to apathetic males and females), quanxibased business ethics and business etiquettes are positively associated with relationship performance.

\section{Data Collection}

We engaged an official research agency to conduct the survey in China. This agency's database has a population of about 2.6 million with approximately 50,000 samples in each province. The company has the IP address of each sample and has reassured us that the respondents were not able to complete the survey more than one time. We provided the agency the profile of the potential respondents. The profile included a general focus on business people or academics with experience in forming a business relationship. This profile allowed us to narrow down the sampling frame to 4158 potential respondents. We then performed simple random sampling without replacement to maximize unbiased representation of the group. Based on our research protocol of randomly selecting every third person, the agency sent out an online invitation letter to the 1386 potential respondents. These respondents were from eight major cities including Beijing, Shanghai, Changchun, Wuhan, and Xian. If they agreed to participate in the survey, the survey link was provided to the potential respondents with the interviewers staying online to answer any queries. A total of 749 respondents took part in the survey. However, only 583 responses were usable resulting in a response rate of $14 \%$. This response rate was comparable to similar online surveys. The demographics of the sample is presented in Table 1.

$>>$ Table 1 about here $<<$

\section{Constructs and Measurement Model}

All construct measures used 7-Point Likert-type scale, see Appendix B for items used to measure each construct.

Business Ethics. Business ethics are organisational and/or moral principles, values, norms and behaviours of individuals or organisations, that guide individual and group behaviour, including the way in which an organisation conducts its business affairs (Rawwas, Arjoon, \& Sidani, 2013; Sparks \& Pan, 2010). Two dimensions of business ethics were measured; Relationship fairness (a 6-item scale) with items adapted from the work of Schwartz (2013) and Koh and Boo (2004), and Relationship stability (a 4-item scale) adapted from Murphy et al. (2007).

Business Etiquette. Business etiquette is a set of manners often upheld by custom and enforced by members of a society in order to provide an environment where members feel comfortable and secure in their social and business interactions (Marchiori et al., 2014; Mukherjee \& Ramos-Salazar, 2014). Two aspects of business etiquette were identified from the literature, Relationship Initiation etiquette and Relationship Quality etiquette, and two dimensions for each were measured. For Relationship Initiation etiquette, Social relation etiquette was measured with eight items adapted from Marchiori et al. (2014) and Rawwas et al. (2013). The Oral etiquette was measure with 4 items adapted from Shapiro, Sheppard, and Cheraskin (1992). For Relationship Quality etiquette, Commitment etiquette was measured with eleven items 
adapted from Doney, Barry, and Abratt (2007); Doney and Cannon (1997); Hoppner, Griffith, and White (2015); and Kumar, Scheer, and Steenkamp (1995). Cultural sensitivity etiquette was measured with two items adapted from Sorndee, Siengthai, and Swierczek (2017).

Business Orientation. Business orientation considers the forward looking or maintenance aspects of cultural work values (Robertson, 2000). Two aspects of business orientation were measured; Goal-Oriented measured with a 4-item scale and Apathetic-Oriented measured with a 4-item scale both scales were adopted from (Robertson, 2000).

Relationship Performance. Relationship performance considers the overall relationship behaviour and reflects the on-going quality of the relationship, not simply relationship behaviours (Hausman, 2001; J. W. Kim, Choi, Qualls, \& Park, 2004). Relationship performance was measured with four items adapted from Z. G. Li and Dant (1997) and Hoppner et al. (2015).

Quanxi. Quanxi is defined as networks of highly adaptive relationships based on formal and informal concepts of reciprocity and social inter-dependence. Quanxi was measured using a single statement. Respondents indicated on a 7-point Likert scale ( $1=$ strongly disagree, $7=$ strongly agree) their agreement with the statement "only through strong family networks/inter-personal connections can one establish a successful business relationship in my selected country". Respondents who scored 5 and above on the scale were considered to have a strong "quanxi" factor.

Business Stages. The four stages of business relationships are defined as; inception, growth, maintenance, and dissolution. Respondents determined the business relationship stage by reading the description and answering the following:

Please think of a recent business transaction that you have undertaken. This business transaction could be Business to Business (e.g., supplier - customer relationship) or Business to Consumer (e.g., getting a haircut, selling a table, or dispensing medications to a customer). The transaction can be goods or a service; it can be a small or a large transaction. Reflecting on this business transaction, how would you classify the stage of your business relationship? Please check one only.

- Inception Stage. Newly acquainted with less than 12 months of business relationship.

- Development Stage. Both myself and this business organization (or person) are committed to the business relationship and there is a high level of input and satisfaction between the two parties.

- Maintenance Stage. Both myself and this business organization (or person) have conducted a number of business transactions. There is an increasing interdependence and trust between the two parties.

- Dissolution Stage. The relationship currently experiences many difficulties including complaints, dissatisfaction of work, disloyalty and poor performance. The relationship is coming to an end.

\section{Control Variables}

Five specific control variables of interest and found informative from previous business and 
cultural research were included as survey questions; gender (male/female), age (under 25 years, 25 to 35,36 to 45,46 to55, 56 to 65 , over 65 years), marital status (single, married/engaged, divorced), business experience (none, 1 to 5 years, 6 to 10 years, 11 to 20 years, over 20 years), and role (either academic or business).

\section{Common Method Variance and Multicollinearity}

Harman's single factor test found no significant common method bias, the maximum variance explained by a single factor is $31,2 \%$, no single factor accounted for more than $50 \%$ of the variance (Podsakoff \& Organ, 1986). Since the ethics and etiquette constructs are similar concepts, multicollinearity was assessed using SPSS. Variance inflation factor (VIF) for the items did not exceed 2.79, indicating no significant multicollinearity (Curto \& Pinto, 2011).

\section{Confirmatory Factor Analysis}

ACFA, using AMOS version 24 was undertaken to confirm and validate the construct measures. (Appendix B summarizes the results of the CFA). The measurement model exceeds the minimum requirements $(\chi 2=1397.5, \mathrm{df}=629, \mathrm{p}<0.001 ; \mathrm{CMIN} / \mathrm{DF}=2.2 ; \mathrm{RMSEA}=0.046$; $\mathrm{SRMR}=052 ; \mathrm{CFI}=0.93 ; \mathrm{TLI}=0.92)$ indicating the items adequately measure the appropriate constructs (Bagozzi \& Yi, 2012). Convergent validity is satisfactory as the items meet or exceed the minimum acceptable criteria; loadings greater than 0.5 on their corresponding factors, Cronbach's Alpha scores greater than 0.70, and AVE (average variance extracted) scores greater than 50\% (Churchill, 1979; Hair, Black, Babin, \& Andersen, 2010).

Discriminant validity overall is acceptable, with low to moderate correlations between the constructs (refer to Table 2), except Commitment etiquette indicates a high correlation with Business Ethics (Relationship stability) (Farrell, 2010).

\section{Table 2 about here $<<$}

\section{RESULTS}

Direct effects and Quanxi mediation effect: Hayes PROCESS Analysis

Hayes PROCESS v3.4 was used to test H1a, b, c and d, holding control and covariate variables constant with 5,000 bootstrap samples and 95\% bootstrap confidence intervals (Hayes, 2017). Refer to Appendix C for detailed results. The H1a quanxi mediation effect was not supported when controlling for relationship stability, social relation etiquette commitment etiquette, cultural sensitivity etiquette, business orientation, gender, age, marital status, business experience and role. Neither Relationship fairness $(\beta=.078, p=.704)$ or Guanxi $(\beta=.027, p$ $=.872$ ) have a significant direct effect on relationship performance, $\mathrm{R}^{2}=.533, F(14,25)=2.04$, $p=.058$. The indirect effect of Relationship fairness on relationship performance through Guanxi was not statistically different from zero $(\beta=-.002)$ with a $95 \%$ bootstrap confidence interval from -0.1254 to 0.2055 . Guanxi does not significantly amplify the effect of relationship fairness on Relationship performance at the Inception stage. Interestingly Commitment etiquette does have a significant positive effect on relationship performance at the Inception 
stage $(\beta=.693, p=.037)$.

In addition, although Relationship fairness significantly influences relationship performance ( $\beta$ $=.354, p>.001)$ at the Growth stage, Guanxi has no significant direct effect $(\beta=.085, p=.082)$, $\mathrm{R}^{2}=.614, F(14,197)=22.35, p<.001$. The indirect effect of Relationship fairness on relationship performance through Guanxi was not statistically different from zero $(\beta=-.018)$ with a $95 \%$ bootstrap confidence interval from -0.0548 to 0.0023 and does not significantly amplify the effect of relationship fairness on relationship performance at the Growth stage. However, both Commitment etiquette $(\beta=.198, p=.042)$ and Goal-oriented business orientation $(\beta=.177, p=.026)$ do have significant positive effects on relationship performance at the Growth stage, while Oral etiquette $(\beta=-.170, p=.013)$ has a significant negative effect on relationship performance.

The H1b quanxi mediation effect is not supported when controlling for relationship fairness, social relation etiquette commitment etiquette, cultural sensitivity etiquette, business orientation, gender, age, marital status, business experience and role. Although both relationship stability $(\beta=.291, p=.004)$ and Guanxi $(\beta=-.148, p=.011)$ have a significant direct effect on relationship performance at the Maintenance stage $\mathrm{R}^{2}=.586, F(14,154)=15.56$, $p<.001$, Guanxi does not significantly amplify the effect of relationship fairness on relationship performance. The indirect effect of relationship stability on relationship performance through Guanxi was not statistically different from zero $(\beta=-.029)$ with a $95 \%$ bootstrap confidence interval from -0.0769 to 0.0093 . However, Goal-oriented business orientation $(\beta=.397, p<.001)$ had a significant positive effect on relationship performance, while Apathy oriented business orientation $(\beta=-.156, p=.026)$ had a significant negative influence on relationship performance.

Neither relationship stability $(\beta=-.015, p=.906)$ or Guanxi $(\beta=-.073, p=.309)$ have a significant direct effect on relationship performance, $\mathrm{R}^{2}=.484, F(14,147)=9.85, p<.001$. The indirect effect of relationship stability on relationship performance through Guanxi was not statistically different from zero $(\beta=.025)$ with a $95 \%$ bootstrap confidence interval from 0.0235 to 0.0376 . Guanxi does not significantly amplify the effect of relationship stability on relationship performance at the Dissolution stage.

The H1c quanxi mediation effect is not supported when controlling for relationship quality etiquette, relationship fairness, relationship stability, business orientation, gender, age, marital status, business experience and role. Neither relationship initiation etiquette $(\beta=-.261, p=.150)$ or Guanxi $(\beta=.104, p=.501)$ have a significant direct effect on relationship performance, $\mathrm{R}^{2}$ $=.498, F(12,27)=2.23, p=.041$. The indirect effect of relationship initiation etiquette on RP through Guanxi was not statistically different from zero $(\beta=.013)$ with a $95 \%$ bootstrap confidence interval from -0.0977 to 0.1446 . Guanxi does not significantly amplify the effect of relationship initiation etiquette on relationship performance at the Inception stage. However, relationship quality etiquette $(\beta=.662, p=.022)$ had a significant positive effect on relationship performance at the Inception stage.

Neither relationship initiation etiquette $(\beta=-.111, p=.074)$ or Guanxi $(\beta=.074, p=.130)$ have a significant direct effect on relationship performance at the Growth stage $\mathrm{R}^{2}=.597$, $F(12,199)=24.53, p<.001$. The indirect effect of relationship initiation etiquette on RP 
through Guanxi was not statistically different from zero $(\beta=.015)$ with a $95 \%$ bootstrap confidence interval from -0.0051 to 0.0428 . Guanxi does not significantly amplify the effect of relationship quality etiquette on relationship performance at the Growth stage. However, Relationship fairness $(\beta=.380, p<.001$ and Goal-oriented business orientation $(\beta=.259, p$ $=.001$ ) had significant positive effects on relationship performance at the Growth stage.

The H1d quanxi mediation effect is not supported when controlling for relationship initiation etiquette, relationship fairness, relationship stability, business orientation, gender, age, marital status, business experience and role. Relationship quality etiquette $(\beta=.151, p=.069)$ does not demonstrate a significant direct effect on relationship performance at the maintenance stage. However, Guanxi $(\beta=-.146, p=.012)$ does show a significant direct effect on relationship performance at the maintenance stage $\mathrm{R}^{2}=.580, F(12,156)=17.96, p<.001$, although the indirect effect of relationship quality etiquette on RP through Guanxi was not statistically different from zero $(\beta=.0004)$ with a $95 \%$ bootstrap confidence interval from -0.0451 to 0.0346. In this case Guanxi does not significantly amplify the effect of relationship quality etiquette on relationship performance at the Maintenance stage of the relationship. Interestingly, relationship stability $(\beta=.328, p<.001)$ and Goal-oriented business orientation $(\beta=.379, p$ $<.001)$ had significant positive effects on relationship performance at the Maintenance stage. Apathy business orientation ( $\beta=-.144, p=.012$ ) showed a significant negative effect on relationship performance.

Neither relationship quality etiquette $(\beta=.217, \mathrm{p}=.056)$ or Guanxi $(\beta=-.047, \mathrm{p}=.485)$ have a significant direct effect on relationship performance $\mathrm{R} 2=.477, F(12,149)=11.31, p<.001$. The indirect effect of relationship quality etiquette on RP through Guanxi was not statistically different from zero $(\beta=.0011)$ with a $95 \%$ bootstrap confidence interval from -0.0225 to 0.0304 . Guanxi does not significantly amplify the effect of relationship quality etiquette on relationship performance at the Dissolution stage. However, Goal-oriented business orientation $(\beta=.334, p<.001)$ had a significant positive effect on relationship performance at the Dissolution stage.

\section{Business orientation}

The results of the impact of business orientation of the respondents on business relationship performance are shown in Table 3. The two orientations, goal-oriented and apathetic-oriented, define the effect of the independent variables. Controlling for gender, age, marital status, business experience and role, hypothesis $2 \mathrm{a}$ is supported, $\mathrm{R}^{2}=.320$, adjusted $\mathrm{R}^{2}=.304, F(12$, $506)=19.83, p<.001$. For high goal-oriented respondents, relationship fairness $(\beta=.176, p<$ $.001)$ had a significant impact on relationship performance. However, hypothesis $2 \mathrm{c}$ is not supported. Neither social relation etiquette $(\beta=.047, p=.292)$ or oral etiquette $(\beta=-.051, p=$ .242) had a significant effect on relationship performance.

Hypothesis $2 \mathrm{~b}$ is not supported, relationship stability is not associated with relationship performance $(\beta=.078, p=.500)$ for high apathetic managers, $\mathrm{R}^{2}=.349$, adjusted $\mathrm{R}^{2}=.282$, $F(12,118)=5.26, p<.001$. Hypothesis $2 \mathrm{~d}$ is not supported, the high apathy-driven businessoriented respondents demonstrated no significant effect from commitment etiquette ( $\beta=.166$, $p=.189)$ or cultural sensitivity etiquette $(\beta=.114, p=.249)$. Although high apathetic managers, with low quanxi, demonstrated a significant cultural sensitivity etiquette $(\beta=.514, p=.026)$ effect on relationship performance, $\mathrm{R}^{2}=.544$, adjusted $\mathrm{R}^{2}=.305, F(11,21)=1.28, p=.05$. 
$>>$ Table 3 about here $<<$

\section{Gender effect: Independent Sample T-Test}

An independent samples t-test was carried out to examine whether there are differences between male and female respondents across the relationship stages (H3). The results showed that there are significant differences between male and female respondents only at the growth stage. At the growth stage, the female respondents placed significantly more emphasis on Relationship stability $(\mathrm{M}=6.21, \mathrm{SD}=0.739)$ than males $(\mathrm{M}=5.94, \mathrm{SD}=0.983), t(160.9)=$ $2.22, p=.028$. Females $(\mathrm{M}=6.06, \mathrm{SD}=0.617)$ also reported significantly greater Commitment etiquette at the growth stage than males $(\mathrm{M}=5.79, \mathrm{SD}=0.813), t(162.2)=2.73, p=.007$. At other stages the differences were not significant. Both $\mathrm{H} 3 \mathrm{a}$ and $\mathrm{H} 3 \mathrm{~b}$ are partially supported. At the growth stage, females focus significantly more than males on relationship stability and commitment etiquette. Females do not exhibit significantly stronger business ethics and business etiquette compared to males at the inception, maintenance, and dissolution stages of a business relationship.

Further analyses were carried out to examine whether males and female respondents with strong quanxi but with different business orientation placed any importance on the business ethics/etiquette variables in order to build lasting business relationship (Hypotheses $4 \mathrm{a}$ and $4 \mathrm{~b}$ ). The results indicate that business relationship success may depend on the respondent's quanxi archetype. Male respondents who are strong quanxi believers with high goal-orientation place significant emphasis on Cultural sensitivity etiquette $(\beta=.197, p=.021)$ when building relationships, $\mathrm{R}^{2}=.339$, adjusted $\mathrm{R}^{2}=.353, F(11,144)=8.69, p<.001$. Supporting Hypothesis $4 \mathrm{a}$, these males are different to both apathy-driven males and females who demonstrate no significant effect for business ethics or business etiquette on relationship performance. Hypothesis $4 \mathrm{~b}$ is also supported, goal-oriented female respondents with strong quanxi place significant emphasis on Commitment etiquette $(\beta=.195, p=.040), \mathrm{R}^{2}=.346$, adjusted $\mathrm{R}^{2}$ $=.304, F(11,174)=8.35, p<.001$, compared to apathetic males and females.

\section{DISCUSSION AND CONCLUSION}

This study analysed the influence of business ethics and etiquette on relationship performance across a business lifecycle. The study was undertaken in China where the practice of quanxi is omnipresent in all facets of life. The overall findings indicate that quanxi does not significantly mediate the ethics or etiquette effect and does not demonstrate an overriding effect on relationship performance. There is no evidence that quanxi provides a clear competitive advantage through the business life-cycle. The findings and interpretation do not support the view that quanxi provides an unfair advantage or facilitates corruption (cf. Fan, 2002; Kadirov et al., 2016).

The results of the study can be summarised under four significant findings. First, from the business ethics perspective, relationship fairness and relationship stability are significant 
drivers of relationship performance at the growth and maintenance stages respectively. As the business relationship grows from the Inception stage, both business partners emphasise mutually beneficial equitable opportunities to grow their business in fairly and responsibly. They adhere to governance transparency and sustain similar moral values. During the maintenance stage, the partnership looks for relational stability. Both parties need to be vigilant to ensure that their partnership continues to strengthen. To do this, the parties focus on developing credibility, keeping promises and maintaining reliability. In China demonstrating relationship stability may involve the practice of combining quanxi and demonstrating commitment to the business relationship. Although previous research indicated that the importance of quanxi would be high at the initial stages (e.g., inception and growth), and would then diminish as business relationships mature (Bews \& Rossouw, 2002; I. Yeung \& Tung, 1996) our findings emphasise the importance of invoking each partner's social capital as their current business relationship matures. That is, as their business relationship matures and in order to further grow the business, each partner will rely on and cultivate the networks of the other partner in order to increase the overall market opportunities.

Second, this study emphasises that in a quality relationship business etiquette, a set of socially acceptable manners and protocols where members of the same society can feel comfortable to interact with each other, should not be underestimated. Commitment etiquette was found to be a significant factor at the Inception and Growth stages of the business relationship. Mutual confidence, meeting commitments, trust, and respect for all parties are some of the quality etiquette protocols that are important to establish and grow the business relationship and for the relationship to thrive. Ironically although quanxi was generally a positive factor during the business relationship stages, the respondents in this study reported quanxi was a significant negative influence during the maintenance stage of the relationship. This implies that business partners would not necessarily draw upon each other's quanxi networks when the business relationship reached the maintenance stage. Such action could be interpreted as a general expectation that being committed and loyal to the immediate business partnership is most important rather than access to partner's networks, which appears to contradict previous findings and interpretations (cf. Hwang \& Staley, 2005; Steidlmeier, 1999; I. Yeung \& Tung, 1996).

Third, business orientation makes a difference in the use of business ethics and etiquette in obtaining relationship performance results. The study found ethical attributes (relational fairness, and relational stability) and commitment etiquette were significant positive factors influencing relationship performance for goal-oriented managers. In contrast, only relationship fairness significantly influenced relationship performance for apathetic-oriented managers. These findings support H. Liu et al. (2004) observation that business orientation has a major effect on performance. Of significant interest are the results showing that goal-orientation had a significant positive effect on relationship performance at the growth, maintenance and dissolution stages of the business relationship, while the apathetic-orientation show a significant negative effect at the maintenance stage. One interpretation is that managers employing quanxi (e.g., quanxi cultivators) utilising positive ethics and etiquette business practices will develop more successful business relationships (R. Y. K. Chan et al., 2002) 
Fourth, there are significant differences between males and females approaches to building business relationship, but only at the growth stage. Female business partners indicated that they maintain comparatively enhanced levels of relationship stability and commitment/loyalty in comparison to their male counterparts. Gilligan and Attanucci (1994) found males and females perceive ethical matters from distinctly different perspective. They argue that females are more willing to foster an ethical approach of caring toward others than males. Further analyses of differences in gender, business orientation and strength of quanxi orientation produced significant results. Male business partners, who are goal-orientated with strong quanxi are more inclined to emphasize cultural sensitivity etiquette in building a successful business relationship. On the other hand, female business partners, who are goal-orientated with strong quanxi are inclined to emphasize commitment etiquette. One interpretation of this results is that males are more likely than females to take a fact-based approach by scanning for threats and challenges in the environment they work-in, and hence may be more attuned to cultural differences and adapt accordingly. They are also more likely to eliminate and isolate issues before making a decision. Female business partners are more likely to personalize, trust, and commit to an undertaking (Annis \& Nesbitt, 2017).

\section{Conclusion, limitations and future research}

In conclusion, the findings of this empirical study provide helpful insights into an area of growing concern to business organizations in China. Despite the numerous studies in this area, few had examined the influence of business ethics and etiquette on relationship performance across business lifecycles or business orientation. The study offers a number of findings which taken onboard would increase an organizations' awareness of the influence of business ethics and etiquette in their relationship building and decision making. However, as with all empirical studies, this study has a number of limitations which can weaken the generalizability of the findings.

The study was conducted in one business environment; China. Although China is considered a high quanxi-oriented society, other East Asian countries also practice and exhibit high levels of quanxi. These other countries should be examined in order to enhance the empirical findings of this study. The sample size for each stage of the relationship lifecycle is small. Hence, it is advisable to treat the findings with caution. Larger samples across multiple countries could gain more reliable results with improved generalizability. This study did not differentiate industries which could be beneficial to understand the prevalence and importance of business ethics and etiquette across business sectors. Future research could involve examination of datasets from other East Asian countries, Middle East countries, Europe, and North and South America. Additional research should consider the expansion of environmental scope, as business digitalisation (e.g., remote partnering and social media) increases age groups, industries, national cultures, values and religious beliefs may influence the acceptance and execution of business ethics and etiquette in each stage of the business relationship lifecycle. 


\section{Appendices}

\section{Appendix A: Ranking results from preliminary study}

Ethics (ranked items)

1 Credibility

2 Commitment to the business relationship

3 Keeping promises

4 Reliability

5 Similar morals

6 Governance transparency

7 Social responsibility

8 Equity \& equal opportunity

9 Fair competition

10 Fairness (General)

\section{SD}

\begin{tabular}{l|l}
6.50 & 0.609
\end{tabular}

\begin{tabular}{l|l}
6.34 & 0.725
\end{tabular}

$6.33 \quad 1.146$

$6.11 \quad 0.950$

$5.61 \quad 1.076$

$5.42 \quad 1.360$

\begin{tabular}{l|l}
5.39 & 1.271
\end{tabular}

$5.33 \quad 1.287$

$5.17 \quad 1.540$

$5.11 \quad 1.545$

$\mathrm{n}=$ sample size (96); 7-point Likert scale

\section{Etiquette (ranked items)}

1 Mutual trust is key to success

2 Meeting commitments

3 Commitment to the relationship

4 Valuing 'Face' and 'Saving Face'

5 Mutual confidence

6 Providing competent solutions

7 Appreciating cultural difference

8 Maintaining confidentiality

9 Loyalty

10 Respect for all parties

11 Developing personal relations

12 Being competent

13 Harmony

14 Cultural adaptability

15 Great host with food

16 Social status consciousness

17 Use of education and personal titles

18 Save Face - attend meetings, accepting invitations

19 Transparency

20 Straight talking

21 Introducing yourself using first name only

22 Providing suitable expensive gifts

23 Expensive gifts

24 Using high pressure sales tactics

25 Gossiping about the client
M SD

\begin{tabular}{l|l|l}
6.42 & 0.614
\end{tabular}

\begin{tabular}{l|l}
6.31 & 0.796
\end{tabular}

$\begin{array}{ll}6.30 & 0.728\end{array}$

$6.21 \quad 0.960$

6.210 .696

$6.16 \quad 0.688$

\begin{tabular}{l|l}
6.14 & 0.772
\end{tabular}

$6.14 \quad 1.115$

\begin{tabular}{l|l}
6.12 & 0.781
\end{tabular}

\begin{tabular}{l|l}
6.09 & 0.723
\end{tabular}

$6.06 \quad 0.776$

$6.03 \quad 1.043$

\begin{tabular}{ll|l}
5.97 & 0.684
\end{tabular}

\begin{tabular}{l|l}
5.91 & 0.981
\end{tabular}

\begin{tabular}{l|l}
5.85 & 0.892
\end{tabular}

\begin{tabular}{ll|l}
5.82 & 1.158
\end{tabular}

\begin{tabular}{|l|l}
5.67 & 1.080 \\
\hline
\end{tabular}

$5.60 \quad 1.143$

$5.58 \quad 1.119$

$4.91 \quad 1.444$

$4.73 \quad 1.526$

$4.20 \quad 1.907$

\begin{tabular}{l|l|l}
4.19 & 1.822
\end{tabular}

\begin{tabular}{ll|l}
4.14 & 1.537
\end{tabular}

$3.30 \quad 1.992$

$\mathrm{n}=$ sample size (96); 7-point Likert scale 
Appendix B: Confirmatory Factor Analysis, showing standardized loadings, Cronbach's Alpha and Average Variance Explained.

\begin{tabular}{|l|c|c|c|c|}
\hline Construct & Loadings & $\begin{array}{c}\text { Cronbach's } \\
\text { Alpha }\end{array}$ & CR & AVE \\
\hline
\end{tabular}

\section{Business Ethics}

\begin{tabular}{|c|c|c|c|c|}
\hline Fair competition & 0.762 & \multirow{5}{*}{0.830} & \multirow{5}{*}{0.834} & \multirow{5}{*}{$72.7 \%$} \\
\hline Equity \& equal opportunity & 0.742 & & & \\
\hline Fairness (General) & 0.706 & & & \\
\hline Social responsibility & 0.689 & & & \\
\hline Governance transparency & 0.637 & & & \\
\hline
\end{tabular}

Relationship stability $($ Mean $=6.22, S D=0.834)$

\begin{tabular}{|c|c|c|c|c|}
\hline Credibility & 0.804 & \multirow{3}{*}{0.826} & \multirow{3}{*}{0.828} & \multirow{3}{*}{$74.3 \%$} \\
\hline Keeping promises & 0.794 & & & \\
\hline Commitment to the business relationship & 0.756 & & & \\
\hline Reliability & $*$ & & & \\
\hline
\end{tabular}

\section{Business Etiquette}

Relationship initiation etiquette

Social relation etiquette $($ Mean $=5.01, S D=0.905)$

\begin{tabular}{|c|c|c|c|c|}
\hline Providing suitable expensive gifts & 0.765 & \multirow{6}{*}{0.847} & \multirow{6}{*}{0.848} & \multirow{6}{*}{$56.8 \%$} \\
\hline Social status consciousness & 0.729 & & & \\
\hline Use of education and personal titles & 0.727 & & & \\
\hline Gift giving is necessary & 0.696 & & & \\
\hline Great host with food & 0.667 & & & \\
\hline Save Face & 0.576 & & & \\
\hline Personal relations & $*$ & & & \\
\hline Valuing 'Face' & $*$ & & & \\
\hline
\end{tabular}

Oral etiquette $($ Mean $=3.53, S D=1.384)$

\begin{tabular}{|c|c|c|c|c|}
\hline Gossiping about the client & 0.818 & \multirow{3}{*}{0.814} & \multirow{3}{*}{0.814} & \multirow{3}{*}{$73.0 \%$} \\
\hline Using high pressure sales tactics & 0.775 & & & \\
\hline Introducing yourself using first name only & 0.715 & & & \\
\hline Straight talking & $*$ & & & \\
\hline
\end{tabular}

Relationship quality etiquette

Commitment etiquette $($ Mean $=6.03, S D=0.710)$

\begin{tabular}{|c|c|c|c|c|}
\hline Mutual confidence & 0.781 & \multirow{7}{*}{0.889} & \multirow{7}{*}{0.892} & \multirow{7}{*}{$56.8 \%$} \\
\hline Meet commitments & 0.771 & & & \\
\hline Mutual trust is key to success & 0.739 & & & \\
\hline Respect for all parties & 0.735 & & & \\
\hline Being competent & 0.694 & & & \\
\hline Providing competent solutions & 0.692 & & & \\
\hline Maintain harmony & 0.667 & & & \\
\hline
\end{tabular}




\begin{tabular}{|c|c|c|c|c|}
\hline Maintaining confidentiality & 0.614 & & & \\
\hline Commitment to the relationship & $*$ & & & \\
\hline Demonstrate loyalty & $*$ & & & \\
\hline Relationship and business transparency & * & & & \\
\hline \multicolumn{5}{|c|}{ Cultural sensitivity etiquette $($ Mean $=5.36, S D=0.968)$} \\
\hline Appreciating cultural difference & 0.832 & \multirow{2}{*}{0.811} & \multirow{2}{*}{0.813} & \multirow{2}{*}{$84.2 \%$} \\
\hline Demonstrate cultural adaptability & 0.823 & & & \\
\hline \multicolumn{5}{|l|}{ Business Orientation } \\
\hline \multicolumn{5}{|l|}{ Goal-Oriented $($ Mean $=5.75, S D=0.712)$} \\
\hline $\begin{array}{l}\text { Managers must be persistent to accomplish } \\
\text { objectives }\end{array}$ & 0.738 & \multirow{4}{*}{0.710} & \multirow{4}{*}{0.719} & \multirow{4}{*}{$53.9 \%$} \\
\hline $\begin{array}{l}\text { It is important to have a conscience in } \\
\text { business }\end{array}$ & 0.652 & & & \\
\hline A good manager knows how to economise. & 0.554 & & & \\
\hline $\begin{array}{l}\text { There is a hierarchy to on-the-job } \\
\text { relationships and it should be observed. }\end{array}$ & 0.546 & & & \\
\hline
\end{tabular}

Apathetic-Oriented (Mean $=3.66, S D=1.355$ )

\begin{tabular}{|c|c|c|c|c|}
\hline $\begin{array}{l}\text { Personal stability is not critical to succeed } \\
\text { in business. }\end{array}$ & 0.808 & \multirow{3}{*}{0.796} & \multirow{3}{*}{0.799} & \multirow{3}{*}{$71.0 \%$} \\
\hline Respect for tradition hampers performance. & 0.780 & & & \\
\hline $\begin{array}{l}\text { Upholding one's personal image makes } \\
\text { little difference in goal achievement. }\end{array}$ & 0.673 & & & \\
\hline $\begin{array}{l}\text { The exchange of favours and gifts is not } \\
\text { necessary to excel }\end{array}$ & * & & & \\
\hline
\end{tabular}

Quanxi business approach $($ Mean $=4.72, \mathrm{SD}=1.401)$

Only through strong family networks/inter-personal connections can one establish a successful business relationship in my selected country

Seven-point Likert scale

Single item measure

Relationship Performance $($ Mean $=5.57, \mathrm{SD}=\mathbf{0 . 6 8 2})$

\begin{tabular}{|c|c|c|c|c|}
\hline $\begin{array}{l}\text { My (my firm's) relationship with the } \\
\text { business organization has been productive. }\end{array}$ & 0.734 & \multirow{4}{*}{0.800} & \multirow{4}{*}{0.805} & \multirow{4}{*}{$62.9 \%$} \\
\hline $\begin{array}{l}\text { I am (my firm is) generally satisfied with } \\
\text { our business relationship. }\end{array}$ & 0.734 & & & \\
\hline $\begin{array}{l}\text { Overall the relationship fully met our } \\
\text { expectations. }\end{array}$ & 0.703 & & & \\
\hline $\begin{array}{l}\text { The time and effort spent in the } \\
\text { relationship has been worthwhile. }\end{array}$ & 0.679 & & & \\
\hline
\end{tabular}

* Items deleted due to loading less than 0.50 , high cross loading ( $>.045)$, and/or theoretical consideration. 
Appendix C: Direct effects and Guanxi indirect effect: Hayes PROCESS Analysis results

\section{H1a: Relationship Fairness (Ethics) x Quanxi}

\begin{tabular}{|c|c|c|c|c|c|c|c|c|c|c|c|}
\hline \multirow[b]{2}{*}{ Construct } & \multicolumn{5}{|c|}{ Inception Stage } & \multicolumn{4}{|c|}{ Growth Stage } & \multirow[b]{2}{*}{$t$-value } & \multirow[b]{2}{*}{$p$} \\
\hline & $\mathrm{B}$ & SE & $\beta$ & $t$-value & $p$ & Construct & $\mathrm{B}$ & SE & $\beta$ & & \\
\hline (Constant) & 3.925 & 1.867 & & 2.103 & 0.046 & (Constant) & 0.822 & 0.441 & & 1.865 & 0.064 \\
\hline Relationship fairness & 0.064 & 0.167 & 0.078 & 0.385 & 0.704 & Relationship fairness & 0.325 & 0.066 & 0.354 & 4.904 & $<.001$ \\
\hline Relationship stability & -0.399 & 0.241 & -0.455 & -1.657 & 0.110 & Relationship stability & 0.062 & 0.068 & 0.076 & 0.915 & 0.361 \\
\hline Social relation etiquette & -0.059 & 0.145 & -0.081 & -0.408 & 0.687 & Social relation etiquette & 0.045 & 0.046 & 0.060 & 0.996 & 0.321 \\
\hline Oral etiquette & -0.077 & 0.096 & -0.166 & -0.809 & 0.426 & Oral etiquette & -0.083 & 0.033 & -0.170 & -2.508 & 0.013 \\
\hline Commitment etiquette & 0.661 & 0.301 & 0.693 & 2.198 & 0.037 & Commitment etiquette & 0.193 & 0.095 & 0.198 & 2.042 & 0.042 \\
\hline Cultural sensitivity etiquette & 0.170 & 0.137 & 0.276 & 1.243 & 0.226 & Cultural sensitivity etiquette & -0.041 & 0.043 & -0.057 & -0.941 & 0.348 \\
\hline Goal oriented & -0.158 & 0.328 & -0.145 & -0.483 & 0.634 & Goal oriented & 0.172 & 0.077 & 0.177 & 2.244 & 0.026 \\
\hline Apathy oriented & -0.022 & 0.073 & -0.053 & -0.307 & 0.761 & Apathy oriented & -0.005 & 0.029 & -0.010 & -0.166 & 0.869 \\
\hline Family networks (Guanxi) & 0.013 & 0.079 & 0.027 & 0.163 & 0.872 & Family networks (Guanxi) & 0.048 & 0.028 & 0.085 & 1.749 & 0.082 \\
\hline Role & -0.427 & 0.353 & -0.268 & -1.211 & 0.237 & Role & 0.001 & 0.111 & 0.001 & 0.012 & 0.990 \\
\hline Gender & 0.210 & 0.215 & 0.164 & 0.980 & 0.337 & Gender & -0.070 & 0.068 & -0.049 & -1.034 & 0.303 \\
\hline Age & -0.007 & 0.146 & -0.008 & -0.046 & 0.964 & Age & 0.017 & 0.055 & 0.015 & 0.315 & 0.753 \\
\hline Marital status & 0.380 & 0.266 & 0.274 & 1.431 & 0.165 & Marital status & 0.157 & 0.091 & 0.082 & 1.723 & 0.087 \\
\hline
\end{tabular}

$$
\mathrm{R}^{2}=0.021 ; F(14,25)=2.040, p=.058 \quad \mathrm{R}^{2}=0.614 ; F(14,197)=22.350, p<.001
$$

The indirect effect of RF on RP through Guanxi was not statistically different from zero $(\beta=-.002)$ with a $95 \%$ bootstrap confidence

The indirect effect of RF on RP through Guanxi was not statistically interval from -0.1254 to 0.2055 . different from zero $(\beta=-.018)$ with a $95 \%$ bootstrap confidence interval from -0.0548 to 0.0023 . 


\begin{tabular}{|c|c|c|c|c|c|c|c|c|c|c|c|}
\hline \multicolumn{6}{|c|}{ Maintenance Stage } & \multicolumn{6}{|c|}{ Dissolution Stage } \\
\hline Construct & $\mathrm{B}$ & SE & $\beta$ & $t$-value & $p$ & Construct & B & SE & $\beta$ & $t$-value & $p$ \\
\hline (Constant) & 1.650 & 0.523 & & 3.153 & 0.002 & (Constant) & 0.664 & 0.655 & & 1.013 & 0.313 \\
\hline Relationship stability & 0.246 & 0.084 & 0.291 & 2.925 & 0.004 & Relationship stability & -0.011 & 0.095 & -0.015 & -0.119 & 0.906 \\
\hline Social relation etiquette & -0.028 & 0.054 & -0.035 & -0.512 & 0.610 & Social relation etiquette & 0.083 & 0.059 & 0.118 & 1.395 & 0.165 \\
\hline Oral etiquette & 0.066 & 0.038 & 0.131 & 1.762 & 0.080 & Oral etiquette & 0.024 & 0.036 & 0.048 & 0.647 & 0.518 \\
\hline Commitment etiquette & 0.140 & 0.095 & 0.155 & 1.474 & 0.142 & Commitment etiquette & 0.233 & 0.137 & 0.235 & 1.705 & 0.090 \\
\hline Cultural sensitivity etiquette & 0.060 & 0.047 & 0.084 & 1.284 & 0.201 & Cultural sensitivity etiquette & 0.062 & 0.057 & 0.092 & 1.094 & 0.276 \\
\hline Goal oriented & 0.370 & 0.069 & 0.397 & 5.348 & $<.001$ & Goal oriented & 0.294 & 0.081 & 0.316 & 3.642 & $<.001$ \\
\hline Apathy oriented & -0.084 & 0.037 & -0.156 & -2.254 & 0.026 & Apathy oriented & 0.030 & 0.041 & 0.057 & 0.749 & 0.455 \\
\hline Family networks (Guanxi) & -0.069 & 0.027 & -0.148 & -2.586 & 0.011 & Family networks (Guanxi) & -0.031 & 0.030 & -0.073 & -1.020 & 0.309 \\
\hline Role & -0.223 & 0.139 & -0.089 & -1.609 & 0.110 & Role & 0.040 & 0.167 & 0.015 & 0.240 & 0.811 \\
\hline Business experience (years) & -0.002 & 0.032 & -0.003 & -0.061 & 0.951 & Business experience (years) & 0.013 & 0.050 & 0.016 & 0.262 & 0.794 \\
\hline Gender & 0.014 & 0.075 & 0.011 & 0.191 & 0.849 & Gender & 0.084 & 0.082 & 0.064 & 1.022 & 0.309 \\
\hline Age & -0.033 & 0.051 & -0.037 & -0.646 & 0.519 & Age & -0.063 & 0.061 & -0.066 & -1.024 & 0.307 \\
\hline Marital status & -0.006 & 0.140 & -0.002 & -0.042 & 0.967 & Marital status & 0.174 & 0.138 & 0.083 & 1.258 & 0.211 \\
\hline
\end{tabular}

$$
\mathrm{R}^{2}=0.586 ; F(14,154)=15.56, p<.001
$$

The indirect effect of RS on RP through Guanxi was not statistically different from zero $(\beta=-.029)$ with a $95 \%$ bootstrap confidence interval from -0.0769 to 0.0093 .

$$
\mathrm{R}^{2}=0.484 ; F(14,147)=9.849, p<.001
$$

The indirect effect of RS on RP through Guanxi was not statistically different from zero $(\beta=.025)$ with a $95 \%$ bootstrap confidence interval from -0.0235 to 0.0376 . 
H1c: Relationship Initiation etiquette x Guanxi

\begin{tabular}{|c|c|c|c|c|c|c|c|c|c|c|c|}
\hline \multicolumn{6}{|c|}{ Inception Stage } & \multicolumn{6}{|c|}{ Growth Stage } \\
\hline Construct & B & SE & $\beta$ & $t$-value & $p$ & Construct & B & SE & $\beta$ & $t$-value & $p$ \\
\hline (Constant) & 4.066 & 1.724 & & 2.359 & 0.026 & (Constant) & 0.985 & 0.427 & & 2.307 & 0.022 \\
\hline Relationship quality etiquette & 0.551 & 0.226 & 0.662 & 2.440 & 0.022 & Relationship quality etiquette & 0.042 & 0.075 & 0.044 & 0.563 & 0.574 \\
\hline Relationship fairness & 0.057 & 0.164 & 0.070 & 0.348 & 0.730 & Relationship fairness & 0.348 & 0.064 & 0.380 & 5.424 & $<.001$ \\
\hline Relationship stability & -0.247 & 0.214 & -0.282 & -1.156 & 0.258 & Relationship stability & 0.118 & 0.066 & 0.144 & 1.788 & 0.075 \\
\hline Goal oriented & -0.072 & 0.278 & -0.066 & -0.261 & 0.796 & Goal oriented & 0.251 & 0.073 & 0.259 & 3.465 & 0.001 \\
\hline Apathy oriented & -0.043 & 0.070 & -0.102 & -0.613 & 0.545 & Apathy oriented & -0.027 & 0.029 & -0.055 & -0.931 & 0.353 \\
\hline Family networks (Guanxi) & 0.049 & 0.072 & 0.104 & 0.682 & 0.501 & Family networks (Guanxi) & 0.043 & 0.028 & 0.074 & 1.521 & 0.130 \\
\hline Role & -0.241 & 0.319 & -0.152 & -0.756 & 0.456 & Role & -0.035 & 0.109 & -0.016 & -0.322 & 0.748 \\
\hline Business experience (years) & 0.012 & 0.108 & 0.021 & 0.110 & 0.913 & Business experience (years) & 0.061 & 0.040 & 0.071 & 1.520 & 0.130 \\
\hline Gender & 0.139 & 0.206 & 0.109 & 0.674 & 0.506 & Gender & -0.030 & 0.067 & -0.021 & -0.450 & 0.653 \\
\hline Age & 0.032 & 0.143 & 0.039 & 0.227 & 0.822 & Age & 0.016 & 0.055 & 0.014 & 0.283 & 0.778 \\
\hline
\end{tabular}

$$
\mathrm{R}^{2}=0.498 ; F(12,27)=2.228, p=.041
$$

The indirect effect of relationship initiation etiquette on RP through Guanxi was not statistically different from zero $(\beta=.013)$ with a $95 \%$ bootstrap confidence interval from -0.0977 to 0.1446 .

$$
\mathrm{R}^{2}=0.597 ; F(12,199)=24.535, p<.001
$$

The indirect effect of relationship initiation etiquette on RP through Guanxi was not statistically different from zero $(\beta=.015)$ with a $95 \%$ bootstrap confidence interval from -0.0051 to 0.0428 . 
Maintenance Stage

Dissolution Stage

\begin{tabular}{|c|c|c|c|c|c|c|c|c|c|c|c|}
\hline Construct & $\mathrm{B}$ & SE & $\beta$ & $t$-value & $p$ & Construct & $\mathrm{B}$ & SE & $\beta$ & $t$-value & $p$ \\
\hline (Constant) & 1.777 & 0.516 & & 3.443 & 0.001 & (Constant) & 0.894 & 0.633 & & 1.411 & 0.160 \\
\hline Relationship initiation etiquette & 0.059 & 0.051 & 0.080 & 1.163 & 0.247 & Relationship initiation etiquette & 0.090 & 0.053 & 0.128 & 1.690 & 0.093 \\
\hline Relationship quality etiquette & 0.146 & 0.080 & 0.151 & 1.832 & 0.069 & Relationship quality etiquette & 0.197 & 0.102 & 0.217 & 1.924 & 0.056 \\
\hline Relationship fairness & 0.032 & 0.064 & 0.038 & 0.500 & 0.618 & Relationship fairness & 0.144 & 0.076 & 0.161 & 1.907 & 0.058 \\
\hline Relationship stability & 0.278 & 0.065 & 0.328 & 4.292 & $<.001$ & Relationship stability & 0.047 & 0.079 & 0.060 & 0.588 & 0.557 \\
\hline Goal oriented & 0.353 & 0.065 & 0.379 & 5.428 & $<.001$ & Goal oriented & 0.310 & 0.080 & 0.334 & 3.890 & $<.001$ \\
\hline Apathy oriented & -0.077 & 0.037 & -0.144 & -2.104 & 0.037 & Apathy oriented & 0.017 & 0.039 & 0.032 & 0.437 & 0.663 \\
\hline Family networks (Guanxi) & -0.068 & 0.027 & -0.146 & -2.559 & 0.012 & Family networks (Guanxi) & -0.020 & 0.028 & -0.047 & -0.699 & 0.485 \\
\hline Role & -0.225 & 0.139 & -0.090 & -1.623 & 0.107 & Role & 0.022 & 0.166 & 0.008 & 0.130 & 0.897 \\
\hline Business experience (years) & -0.005 & 0.031 & -0.009 & -0.170 & 0.865 & Business experience (years) & 0.008 & 0.049 & 0.010 & 0.166 & 0.869 \\
\hline Gender & 0.009 & 0.074 & 0.007 & 0.124 & 0.902 & Gender & 0.078 & 0.081 & 0.059 & 0.958 & 0.339 \\
\hline Age & -0.036 & 0.051 & -0.041 & -0.711 & 0.478 & Age & -0.068 & 0.061 & -0.071 & -1.116 & 0.266 \\
\hline Marital status & -0.035 & 0.137 & -0.014 & -0.254 & 0.800 & Marital status & 0.182 & 0.138 & 0.087 & 1.324 & 0.188 \\
\hline
\end{tabular}

The indirect effect of relationship quality etiquette on RP through

The indirect effect of relationship quality etiquette on RP through

Guanxi was not statistically different from zero $(\beta=.0004)$ with a 95\% Guanxi was not statistically different from zero $(\beta=.0011)$ with a 95\% bootstrap confidence interval from -0.0451 to 0.0346 .

bootstrap confidence interval from -0.0225 to 0.0304 . 


\section{REFERENCES}

Akrout, H., Diallo, M. F., Akrout, W., \& Chandon, J.-L. (2016). Affective trust in buyer-seller relationships: A two-dimensional scale. The Journal of Business \& Industrial Marketing, 31(2), 260-273.

Ambler, T., Witzel, M., \& Xi, C. (2017). Doing business in China (4th ed. ed.). London: Routledge.

Anderson, E., \& Weitz, B. (1989). Determinants of continuity in conventional industrial channel dyads. Marketing Science, 8(4), 310-323.

Annis, B., \& Nesbitt, R. (2017). Results at the top : Using gender intelligence to create breakthrough growth. Hoboken, New Jersey: Wiley.

Arnold, K., \& Bianchi, C. (2001). Relationship marketing, gender, and culture: Implications for consumer behavior. Advances In Consumer Research, Vol Xxviii, 28, 100-105.

Au, A. K. M., \& Wong, D. S. N. (2000). The impact of Guanxi on the ethical decision-making process of auditors - an exploratory study on Chinese CPAs in Hong Kong. Journal of Business Ethics, 28(1), 87-93. doi:10.1023/A:1006117021164

Bader, A. K., Froese, F. J., Achteresch, A., \& Behrens, S. (2017). Expatriates' influence on the affective commitment of host country nationals in China: The moderating effects of individual values and status characteristics. European Journal of International Management, 11(2), 181-200. doi:10.1504/EJIM.2017.082532

Bagozzi, R. P., \& Yi, Y. (2012). Specification, evaluation, and interpretation of structural equation models. Journal of the Academy of Marketing Science, 40(1), 8-34.

Bejou, D., Ennew, C. T., \& Palmer, A. (1998). Trust, ethics and relationship satisfaction. International Journal of Bank Marketing, 16(4), 170-175.

Bennett, R. C., \& Cooper, R. G. (1979). Beyond the marketing concept. Business Horizons, 22(3), 76-83. doi:10.1016/0007-6813(79)90088-0

Bews, N., \& Rossouw, G. (2002). A role for business ethics in facilitating trustworthiness. Journal of Business Ethics, 39(4), 377-390. doi:10.1023/A:1019700704414

Bian, Y. (2017). The comparative significance of Guanxi. Management and Organization Review, 13(2), 261-267. doi:10.1017/mor.2017.20

Bian, Y. (2018). The prevalence and the increasing significance of Guanxi. 235, 597-621. doi:10.1017/S0305741018000541

Bian, Y. (2019). Guanxi, how China works. Hoboken, NJ: John Wiley \& Sons.

Brettel, M., Land, S., Thalmann, J., \& Austermann, D. (2012). Regularly submitted papers cultural differences in leadership in SMEs: New product development in China and germany. European Journal of International Management, 6(6), 651-675. doi:10.1504/EJIM.2012.050421

Brunner, J. A., Chen, J., Sun, C., \& Zhou, N. (1990). The role of Guanxi in negotiations in the Pacific Basin. Journal of Global Marketing, 3(2), 7-24. doi:10.1300/J042v03n02_02

Brush, C. G. (1992). Research on women business owners: Past trends, a new perspective and future directions. Entrepreneurship Theory and Practice, 16(4), 5-30. doi: $10.1177 / 104225879201600401$

$\mathrm{Bu}$, N., \& Roy, J.-P. (2005). Career success networks in China: Sex differences in network composition and social exchange practices. Asia Pacific Journal of Management, 22(4), 
381-403. doi:10.1007/s10490-005-4116-X

Burnaz, S., Atakan, M. G. S., Topcu, Y. I., \& Singhapakdi, A. (2009). An exploratory crosscultural analysis of marketing ethics: The case of Turkish, Thai, and American businesspeople. Journal of Business Ethics, 90, 371-382.

Chan, N. L., \& Guillet, B. D. (2011). Investigation of social media marketing: How does the hotel industry in Hong Kong perform in marketing on social media websites? Journal of Travel \& Tourism Marketing, 28(4), 345-368.

Chan, R. Y. K., Cheng, L. T. W., \& Szeto, R. W. F. (2002). The dynamics of guanxi and ethics for Chinese executives. Journal of Business Ethics, 41(4), 327-336. doi:http://dx.doi.org/10.1023/A:1021230831161

Chen, X.-P., \& Chen, C. (2004). On the intricacies of the Chinese Guanxi : A process model of Guanxi development. Asia Pacific Journal of Management, 21(3), 305-324. doi:10.1023/B:APJM.0000036465.19102.d5

Choi, S., \& Messinger, P. R. (2016). The role of fairness in competitive supply chain relationships: An experimental study. European Journal of Operational Research, 251(3), 798-813. doi:10.1016/j.ejor.2015.12.001

Chung, H. F. L. (2019). How guanxi networking matters in the relation between market orientation and innovation in asian emerging economies - the case of Markor. Journal of Business \& Industrial Marketing, 34(4), 836-849. doi:10.1108/JBIM-05-2017-0115

Chung, H. F. L., \& Kuo, T. (2018). When and how managerial ties matter in international competitive strategy, export financial and strategic performance framework. European Journal of Marketing, 52(1/2), 260-278. doi:10.1108/EJM-05-2015-0305

Churchill, G. A., Jr. (1979). A paradigm for developing better measures of marketing constructs. Journal of Marketing Research, 16(1), 64-73.

Crane, A., Matten, D., Glozer, S., \& Spence, L. (2019). Business ethics: Managing corporate citizenship and sustainability in the age of globalization (Fifth edition. ed.). Oxford: Oxford University Press.

Curto, J. D., \& Pinto, J. C. (2011). The corrected vif(cvif). Journal of Applied Statistics, 38(7), 1499-1507.

De Mente, B. L. (2016). Etiquette guide to China : Know the rules that make the difference! North Clarendon: Tuttle Publishing.

Deale, C. S., \& Lee, S.-H. (2019). An exploratory study of hospitality and tourism stakeholders' perceptions of professional etiquette. Journal of Hospitality \& Tourism Education, 114. doi:10.1080/10963758.2019.1654891

DesJardins, J. R., \& McCall, J. J. (2014). Contemporary issues in business ethics (6th ed.). Stamford, CT: Cengage Learning.

Ding, Z., Vuchkovski, D., Žabkar, V., Hirose, M., \& Rašković, M. (2018). Ljubljana to Tokyo: Understanding drivers of young-adult consumer innovativeness and the role of regionalism in Eastern Europe and East Asia. Journal of East European Management Studies, 23(3), 502-522. doi:10.5771/0949-6181-2018-3-502

Doney, P. M., Barry, J. M., \& Abratt, R. (2007). Trust determinants and outcomes in global b2b services. European Journal of Marketing, 41(9/10), 1096-1116. doi:10.1108/03090560710773363

Doney, P. M., \& Cannon, J. P. (1997). An examination of the nature of trust in buyer-seller 
relationships. Journal of Marketing, 61(2), 35-51.

Dunfee, T. W., \& Warren, D. E. (2001). Is Guanxi ethical? A normative analysis of doing business in China. Journal of Business Ethics, 32(3), 191-204. doi:10.1023/A:1010766721683

Fam, K.-S., \& Waller, D. S. (2008). Agency-client relationship factors across life-cycle stages. Journal of Relationship Marketing, 7(2), 217-236. doi:10.1080/15332660802279503

Fan, Y. (2002). Questioning guanxi: Definition, classification and implications. International Business Review, 11(5), 543-561. doi:http://dx.doi.org/10.1016/S0969-5931(02)00036$\underline{7}$

Farh, J.-L., Tsui, A., S., Xin, K., \& Cheng, B.-S. (1998). The influence of relational demography and Guanxi: The Chinese case. Organization Science, 9(4), 471-488. doi:10.1287/orsc.9.4.471

Farrell, A. M. (2010). Insufficient discriminant validity: A comment on Bove, Pervan, Beatty, and Shiu (2009). Journal of Business Research, 63(3), 324-327. doi:https://doi.org/10.1016/j.jbusres.2009.05.003

Ferrell, O. C., Fraedrich, J., \& Ferrell, L. (2015). Business ethics: Ethical decision making and cases (10th ed.). Stamford, CT: Cengage learning.

Fonfara, K., Ratajczak-Mrozek, M., \& Leszczyński, G. (2018). Change in business relationships and networks: Concepts and business reality. Industrial Marketing Management, 70, 1-4. doi:10.1016/j.indmarman.2017.09.016

Ghauri, P., \& Fang, T. (2001). Negotiating with the Chinese: A socio-cultural analysis. Journal of World Business, 36(3), 303-325. doi:10.1016/S1090-9516(01)00057-8

Gilligan, C., \& Attanucci, J. (1994). Two moral orientations: Gender differences and similarities. In B. Puka (Ed.), Caring voices and women's moral frames: Gilligan's view. (pp. 123-137). New York, NY: Garland Publishing.

Gilliland, S. W. (1993). The perceived fairness of selection systems: An organizational justice perspective. Academy of Management Review, 18(4), 694.

Gold, T., Guthrie, D., \& Wank, D. L. (2002). Social connections in China institutions, culture, and the changing nature of Guanxi. Cambridge, UK: Cambridge University Press.

Graham, J. L., \& Lam, N. M. (2003). The Chinese negotiation. Harvard Business Review, 81(10), 82-91.

Guo, Y., Rammal, H. G., Benson, J., Zhu, Y., \& Dowling, P. J. (2018). Interpersonal relations in China: Expatriates' perspective on the development and use of guanxi. International Business Review, 27(2), 455-464. doi:10.1016/j.ibusrev.2017.09.012

Hair, J. F., Jr., Black, W. C., Babin, B. J., \& Andersen, R. E. (2010). Mutilvariate data analysis: A global perspective (7th ed.). Upper Saddle River, NJ: Pearson Prentice Hall.

Hausman, A. (2001). Variations in relationship strength and its impact on performance and satisfaction in business relationships. Journal of Business \& Industrial Marketing, 16(6/7), 600-616.

Hayes, A. F. (2017). Introduction to mediation, moderation, and conditional process analysis: A regression-based approach (2nd ed.). New York, NY: Guilford Publications.

Ho, T. H., Su, X., \& Wu, Y. (2014). Distributional and peer - induced fairness in supply chain contract design. Production and Operations Management, 23(2), 161-175. doi:10.1111/poms.12064 
Hoppner, J. J., Griffith, D. A., \& White, R. C. (2015). Reciprocity in relationship marketing: A cross-cultural examination of the effects of equivalence and immediacy on relationship quality and satisfaction with performance. Journal of International Marketing, 23(4), 64-83.

Hui, C., \& Graen, G. (1997). Guanxi and professional leadership in contemporary sinoAmerican joint ventures in mainland China. The Leadership Quarterly, 8(4), 451-465. doi:10.1016/S1048-9843(97)90024-2

Hunt, S. D. (2019). The ethics of branding, customer-brand relationships, brand-equity strategy, and branding as a societal institution. Journal of Business Research, 95, 408-416. doi:https://doi.org/10.1016/j.jbusres.2018.07.044

Hussain, J. G. (2010). "Enter the dragoness": Firm growth, finance, guanxi, and gender in China. Gender in Management: An International Journal, 25(2), 137-156. doi:10.1108/17542411011026302

Hwang, D. B. K., Golemon, P., Chen, Y., Wang, T.-S., \& Hung, W.-S. (2009). Guanxi and business ethics in Confucian society today: An empirical case study in taiwan. Journal of Business Ethics, 89(2), 235-250. doi:10.1007/s10551-008-9996-5

Hwang, D. B. K., \& Staley, A. B. (2005). An analysis of recent accounting and auditing failures in the united states on us accounting and auditing in China. Managerial Auditing Journal, 20(3), 227-234. doi:10.1108/02686900510585573

Jacobs, J. B. (1982). The concept of guanxi and local politics in a rural Chinese cultural setting. In S. L. Greenblatt, R. W. Wilson, \& A. A. Wilson (Eds.), Social interaction in Chinese society (pp. 209-236): Praeger Publishers.

Jiang, Z., Shiu, E., Henneberg, S., \& Naude, P. (2016). Relationship quality in business to business relationships-reviewing the current literatures and proposing a new measurement model. Psychology \& Marketing, 33(4), 297-313. doi:10.1002/mar.20876

Kadirov, D. (2018). Towards a theory of marketing systems as the public good. Journal of Macromarketing, 38(3), 278-297. doi:10.1177/0276146718767949

Kadirov, D., \& Varey, R. J. (2011). Symbolism in marketing systems. Journal of Macromarketing, 31(2), 160-171. doi:10.1177/0276146710393519

Kadirov, D., Varey, R. J., \& Wolfenden, S. (2016). Investigating chrematistics in marketing systems: A research framework. Journal of Macromarketing, 36(1), 54-67. doi: $10.1177 / 0276146715608500$

Kim, J. W., Choi, J., Qualls, W., \& Park, J. (2004). The impact of CRM on firm - and relationship - level performance in distribution networks. Communications of the Association for Information Systems, 14, 632-652.

Kim, T.-Y., \& Leung, K. (2007). Forming and reacting to overall fairness: A cross-cultural comparison. Organizational Behavior and Human Decision Processes, 104(1), 83-95. doi:10.1016/j.obhdp.2007.01.004

Koh, H. C., \& Boo, E. f. H. Y. (2004). Organisational ethics and employee satisfaction and commitment. Management Decision, 42(5), 677-693. doi:doi:10.1108/00251740410538514

Kumar, N., Scheer, L. K., \& Steenkamp, J.-B. E. M. (1995). The effects of perceived interdependence on dealer attitudes. Journal of Marketing Research, 32(3), 348-356.

Laczniak, G. R., \& Murphy, P. E. (2019). The role of normative marketing ethics. Journal of 
Business Research, 95, 401-407. doi:10.1016/j.jbusres.2018.07.036

Lawler, E. J. (2001). An affect theory of social exchange. American Journal of Sociology, 107(2), 321-352. doi:10.1086/324071

Leung, T. K. P., \& Barnes, B. R. (2019). Ethical cronyism: An insider approach for building guanxi and leveraging business performance in China. Asia Pacific Business Review, 1-25. doi:10.1080/13602381.2019.1654215

Leung, T. K. P., \& Wong, Y. H. (2001). The ethics and positioning of guanxi in China. Marketing Intelligence \& Planning, 19(1), 55-64. doi:10.1108/02634500110363826

Li, P.-Y., Huang, K.-F., Xu, K., \& Yu, C.-M. J. (2018). The effect of local environment on innovation: A comparison of local and foreign firms in China. European Journal of International Management, 12(4), 447-471. doi:10.1504/EJIM.2018.092845

Li, Z. G., \& Dant, R. P. (1997). An exploratory study of exclusive dealing in channel relationships. Journal of the Academy of Marketing Science, 25(3), 201-213.

Littrell, R. F., Alon, I., \& Wai Chan, K. (2012). Regional differences in managerial leader behaviour preferences in China. Cross Cultural Management: An International Journal, 19(3), 315-335. doi:10.1108/13527601211247071

Liu, H., Roos, L.-U., \& Wensley, R. (2004). The dynamics of business orientation: The case of the Volvo car corporation. Industrial Marketing Management, 33(4), 333-344.

Liu, J. (2017). Gender, sexuality and power in Chinese companies beauties at work (1st ed. 2017. ed.). London: Palgrave Macmillan UK.

Liu, Y., Huang, Y., Luo, Y., \& Zhao, Y. (2012). How does justice matter in achieving buyersupplier relationship performance? Journal of Operations Management, 30(5), 355-367. doi:10.1016/j.jom.2012.03.003

Longstreth, M., Stafford, K., \& Mauldin, T. (1987). Self-employed women and their families: Time use and socioeconomic characteristics. Journal of Small Business Management, $25,30-37$.

Lovett, S., Simmons, L., C., \& Kali, R. (1999). Guanxi versus the market: Ethics and efficiency. Journal of International Business Studies, 30(2), 231-248. doi:10.1057/palgrave.jibs. 8490068

Lynch, J., Mason, R. J., Beresford, A. K. C., \& Found, P. A. (2012). An examination of the role for business orientation in an uncertain business environment. International Journal of Production Economics, 137(1), 145-156. doi:https://doi.org/10.1016/j.ijpe.2011.11.004

Marchiori, B. E., Carraher, C. E., \& Stiles, K. (2014). Understanding and overcoming business etiquette differences in Japan, Turkey, and the United States of America. Journal of Technology Management in China, 9(3), 274-288. doi:http://dx.doi.org/10.1108/JTMC$\underline{08-2014-0045}$

McLaren, A. E. (2004). Women's work and ritual space in China. In A. E. McLaren (Ed.), Chinese women, living and working (pp. 169-187). London: RoutledgeCurzon.

Michell, P., Reast, J., \& Lynch, J. (1998). Exploring the foundations of trust. Journal of Marketing Management, 14(1-3), 159-172. doi:10.1362/026725798784959417

Miles, M. P., Crispin, S., \& Kasouf, C. J. (2011). Entrepreneurship's relevance to marketing. Journal of Research in Marketing and Entrepreneurship, 13(2), 126-136. doi:doi:10.1108/14715201111176417

Mukherjee, S., \& Ramos-Salazar, L. (2014). "Excuse us, your manners are missing!" The role 
of business etiquette in today's era of cross- cultural communication. TSM Business Review, 2(1), 18-28.

Murphy, P. E., Laczniak, G. R., \& Wood, G. (2007). An ethical basis for relationship marketing: A virtue ethics perspective. European Journal of Marketing, 41(1/2), 37-57. doi:doi:10.1108/03090560710718102

Ndubisi, N. O. (2006). Effect of gender on customer loyalty: A relationship marketing approach. Marketing Intelligence \& Planning, 24(1), 48-61. doi:10.1108/02634500610641552

Nee, V., \& Opper, S. (2010). Political capital in a market economy. Social Forces, 88(5), 21052132. doi:10.1353/sof.2010.0039

O'Fallon, M. J., \& Butterfield, K. D. (2005). A review of the empirical ethical decision-making literature: 1996-2003. Journal of Business Ethics, 59(4), 375-413. doi:10.1007/s10551005-2929-7

Opper, S., Nee, V., \& Holm, H. J. (2017). Risk aversion and Guanxi activities:: A behavioral analysis of CEOs in China. Academy of Management Journal, 60(4), 1504-1530. doi:10.5465/amj.2015.0355

Oyedijo, A., Yang, Y., Hicks, C., \& Dong, J. (2018). Fairness in supply chain relationships: The value and consequence for reputation and sustainability. Paper presented the The Susilo Institute for Ethics in the Global Economy 3rd Annual Symposium, Newcastle University.

Painter-Morland, M. (2008). Business ethics as practice: Ethics as the everyday business of business. Cambridge, UK: Cambridge University Press.

Podsakoff, P. M., \& Organ, D. W. (1986). Self-reports in organizational research: Problems and prospects. Journal of Management, 12(4), 531-544. doi:http://dx.doi.org/10.1177/014920638601200408

Qian, L., Yang, P., \& Li, Y. (2016). Does guanxi in China always produce value? The contingency effects of contract enforcement and market turbulence. Journal of Business \& Industrial Marketing, 31(7), 861-876. doi:10.1108/JBIM-08-2015-0142

Qiu, T. (2018). Dependence concentration and fairness perceptions in asymmetric supplierbuyer relationships. Journal of Marketing Management, 34(3-4), 395-419. doi:10.1080/0267257X.2018.1450281

Rawwas, M. Y. A., Arjoon, S., \& Sidani, Y. (2013). An introduction of epistemology to business ethics: A study of marketing middle-managers. Journal of Business Ethics, 117(3), 525539. doi:http://dx.doi.org/10.1007/s10551-012-1537-6

Rawwas, M. Y. A., Wang, Y., Zhao, B., \& Javed, B. (2018). A comparison between north and south business ethics: The concepts of renzhi and fazhi in China. Asia Pacific Business Review, 24(5), 585-601. doi:10.1080/13602381.2018.1495381

Rempel, J. K., Holmes, J. G., \& Zanna, M. P. (1985). Trust in close relationships. Journal of Personality and Social Psychology, 49(1), 95-112. doi:10.1037/0022-3514.49.1.95

Robertson, C. J. (2000). The global dispersion of Chinese values: A three-country study of confucian dynamism. Management International Review, 40(3), 253-268.

Rosa, P., Carter, S., \& Hamilton, D. (1996). Gender as a determinant of small business performance: Insights from a british study. Small Business Economics, 8(6), 463-478. doi:10.1007/BF00390031

Sardy, M., Munoz, J. M., Jianmin Sun, J., \& Alon, I. (2010). Dimensionality of business ethics 
in China. Competitiveness Review: An International Business Journal, 20(1), 6-30. doi:10.1108/10595421011019948

Schaffer, B. F., \& Kelley, C. A. (1993). Education in business etiquette: Attitudes of marketing professionals. Journal of Education for Business, 68(6), 330-333. doi:http://dx.doi.org/10.1080/08832323.1993.10117637

Schwartz, M. S. (2013). Developing and sustaining an ethical corporate culture: The core $\begin{array}{llll}\text { elements. } & \text { Business }\end{array}$ doi:http://dx.doi.org/10.1016/j.bushor.2012.09.002

Scott, J. M., Harrison, R. T., Hussain, J., \& Millman, C. (2014). The role of guanxi networks in the performance of women-led firms in China. International Journal of Gender and Entrepreneurship, 6(1), 68-82. doi:10.1108/IJGE-03-2013-0014

Seligman, S. D. (2008). Chinese business etiquette: A guide to protocol, manners, and culture in the people's republic of China: Grand Central Publishing.

Shapiro, D. L., Sheppard, B. H., \& Cheraskin, L. (1992). Business on a handshake. Negotiation Journal, 8(4), 365-377. doi:10.1111/j.1571-9979.1992.tb00679.x

Shaw, W. H., Barry, V., Issa, T., \& Catley, B. (2013). Moral issues in business (2nd ed.). South Melbourne, Victoria: Cengage Australia.

Singhapakdi, A., Kraft, K. L., Vitell, S. J., \& Rallapalli, K. C. (1995). The perceived importance of ethics and social responsibility on organizational effectiveness: A survey of marketers. Journal of the Academy of Marketing Science, 23(1), 49-56. doi:10.1007/bf02894611

Singhapakdi, A., Marta, J. K. M., Rao, C. P., \& Cicic, M. (2001). Is cross-cultural similarity an indicator of similar marketing ethics? Journal of Business Ethics, 32(1), 55-68. doi:10.1023/a:1010699529874

Sorndee, K., Siengthai, S., \& Swierczek, F. W. (2017). Closing cultural distance: The cultural adaptability in Chinese-related firms in Thailand. Journal of Asia Business Studies, 11(2), 229-250. doi:10.1108/JABS-07-2016-0097

Sparks, J. R., \& Pan, Y. (2010). Ethical judgments in business ethics research: Definition, and research agenda. Journal of Business Ethics, 91(3), 405-418.

Stead, W., Worrell, D., \& Stead, J. (1990). An integrative model for understanding and managing ethical behavior in business organizations. Journal of Business Ethics, 9(3), 233-242. doi:10.1007/BF00382649

Steidlmeier, P. (1999). Gift giving, bribery and corruption: Ethical management of business relationships in China. Journal of Business Ethics, 20(2), 121-132. doi:10.1023/A:1005960026519

Su, C., \& Littlefield, J. (2001). Entering Guanxi: A business ethical dilemma in mainland China? Journal of Business Ethics, 33(3), 199-210. doi:10.1023/A:1017570803846

Tang, L. (2019). Gendered and sexualized guanxi: The use of erotic capital in the workplace in urban China. Asia Pacific Business Review, 1-19. doi:10.1080/13602381.2019.1701264

Thomson, A. (1999). Critical reasoning in ethics: A practical introduction. London, UK: Routledge.

Wang, C. L., Siu, N. Y. M., \& Barnes, B. R. (2008). The significance of trust and renqing in the long-term orientation of Chinese business-to-business relationships. Industrial 
Marketing Management, 37(7), 819-824. doi:10.1016/j.indmarman.2008.01.008

Warner, M., \& Zhu, Y. (2018). The challenges of managing 'new generation' employees in contemporary China: Setting the scene. Asia Pacific Business Review, 24(4), 429-436. doi:10.1080/13602381.2018.1451130

Weber, M. R., Finley, D. A., Crawford, A., \& Rivera, D. (2009). An exploratory study identifying soft skill competencies in entry-level managers. Tourism and Hospitality Research, 9(4), 353-361. doi:10.1057/thr.2009.22

Wilpert, B., \& Scharpf, S. (1990). Intercultural management - joint ventures in the peoplesrepublic-of-china. International Journal of Psychology, 25(5-6), 643-656.

Wong, Y. H. (1998). Key to key account management: Relationship (guanxi) model. International Marketing Review, 15(4), 215-231.

$\mathrm{Xu}, \mathrm{K} .$, \& Li, Y. (2015). Exploring guanxi from a gender perspective: Urban Chinese women's practices of guanxi. Gender, Place \& Culture, 22(6), 833-850. doi:10.1080/0966369X.2014.917279

Yang, M. M.-H. (2016). Gifts, favors, and banquets : The art of social relationships in China. Ithaca: Cornell University Press.

Yeung, H. W.-c. (2008). Hybrid capitalism: A new breed of Chinese entrepreneurship in a global era. In R. S.-K. Wong (Ed.), Chinese entrepreneurship in a global era (pp. 2952). Abingdon, UK: Taylor \& Francis.

Yeung, I., \& Tung, R. (1996). Achieving business success in Confucian societies: The importance of Guanxi (connections). Organizational Dynamics, 25(2), 54-65.

Yin, J., \& Quazi, A. (2018). Business ethics in the greater China region: Past, present, and future research. Journal of Business Ethics, 150(3), 815-835. doi:10.1007/s10551-016$3220-9$

Zhang, N. (2006). Social networks and women's rural-urban migration in contemporary China. Labour, Capital and Society / Travail, capital et société, 39(2), 104-125. 
Figure 1. Quanxi business relationships archetypes

\begin{tabular}{l|l|l|l}
\hline \multicolumn{2}{c|}{} & \multicolumn{2}{c}{ Gender } \\
\cline { 3 - 4 } \multicolumn{2}{c}{ Business Orientation } & Male & \multicolumn{1}{c}{ Female } \\
\cline { 2 - 4 } & Goal-Oriented & Goal oriented male & Goal oriented female \\
\cline { 2 - 4 } & Apathy-driven & Apathy-driven male & Apathy-driven female \\
\hline
\end{tabular}


Table 1: Sample demographics

\begin{tabular}{l|c|c}
\hline & Frequency & \% \\
\hline Occupation & & \\
\hline An academic & 55 & 9.4 \\
\hline A business person & 528 & 91 \\
\hline Role & & \\
\hline Role as a Seller & 346 & 59 \\
\hline Role as a Buyer & 237 & 41 \\
\hline Gender & & \\
\hline Male & 265 & 46 \\
\hline Female & 318 & 55 \\
\hline Relationship Stage & & \\
\hline Inception & 40 & 6.9 \\
\hline Growth & 212 & 36 \\
\hline Maintenance & 169 & 29 \\
\hline Dissolution & 162 & 28 \\
\hline Business Experience & & \\
\hline 1 to 5 years of experience & 16 & 2.7 \\
\hline 6 to 10 years of experience & 185 & 32 \\
\hline 11 to 20 years of experience & 252 & 43 \\
\hline Over 20 years of experience & 101 & 17 \\
\hline No experience & 29 & 5 \\
\hline Age & & \\
\hline Age under 25 & 21 & 3.6 \\
\hline Age 25-35 & 366 & 63 \\
\hline Age 36-45 & 158 & 27 \\
\hline Age 46-55 & 30 & 5.1 \\
\hline Age 56-65 & 8 & 1.4 \\
\hline
\end{tabular}

$\mathrm{n}=583$ 
Table 2: Construct correlations

\begin{tabular}{ll|c|c|c|c|c|c|c|c}
\hline & \multicolumn{2}{c}{ FM } & \multicolumn{2}{c}{ R } & \multicolumn{2}{c}{ SB } & \multicolumn{2}{c}{ OP } & \multicolumn{2}{c}{ C\&L } & \multicolumn{2}{c}{ CI } & \multicolumn{2}{c}{ GO } & \multicolumn{2}{c}{ AO } & \multicolumn{1}{c}{ RP } \\
\hline Relationship fairness & 1.000 & 0.575 & 0.304 & 0.004 & 0.650 & 0.517 & 0.520 & -0.083 & 0.553 \\
Relationship stability & & 1.000 & 0.195 & -0.296 & 0.815 & 0.426 & 0.647 & -0.302 & 0.597 \\
$\begin{array}{l}\text { Social relation etiquette } \\
\text { Oral etiquette }\end{array}$ & & 1.000 & 0.337 & 0.285 & 0.451 & 0.350 & 0.198 & 0.244 \\
Commitment etiquette & & & & 1.000 & -0.237 & 0.066 & -0.191 & 0.558 & -0.162 \\
Cultural sensitivity etiquette & & & & 1.000 & 0.470 & 0.687 & -0.302 & 0.658 \\
Goal-Oriented & & & & & 1.000 & 0.446 & -0.033 & 0.392 \\
Apathetic-Oriented & & & & & & & 1.000 & -0.205 & 0.613 \\
Relationship Performance & & & & & & & & 1.000 & -0.243 \\
\hline
\end{tabular}


Table 3: Multiple Regression Analysis, Business Ethics and Etiquette variables by Goal and Apathy business orientation effect on Relationship Performance

\begin{tabular}{lc|c|c|c|c}
\hline High Goal Orientation & $\mathrm{B}$ & $\mathrm{SE}$ & $\beta$ & $t$-value & $p$ value \\
\hline (Constant) & 1.381 & 0.360 & & 3.833 & $<.001$ \\
Relationship fairness & 0.148 & 0.040 & 0.176 & 3.675 & $<.001$ \\
Relationship stability & 0.125 & 0.052 & 0.127 & 2.410 & 0.016 \\
Social relation etiquette & 0.032 & 0.030 & 0.047 & 1.055 & 0.292 \\
Oral etiquette & -0.021 & 0.018 & -0.051 & -1.171 & 0.242 \\
Commitment etiquette & 0.317 & 0.061 & 0.286 & 5.168 & $<.001$ \\
Cultural sensitivity etiquette & 0.039 & 0.030 & 0.059 & 1.324 & 0.186 \\
Family networks (Guanxi) & -0.006 & 0.016 & -0.015 & -0.383 & 0.702 \\
Role & 0.070 & 0.081 & 0.032 & 0.857 & 0.392 \\
Business experience (years) & 0.023 & 0.023 & 0.038 & 1.007 & 0.314 \\
Gender & -0.040 & 0.045 & -0.034 & -0.901 & 0.368 \\
Age & 0.015 & 0.032 & 0.018 & 0.469 & 0.639 \\
Marital status & 0.133 & 0.068 & 0.075 & 1.944 & 0.052 \\
\hline Depency
\end{tabular}

Dependent Variable: Relationship Performance

Selecting only cases for which Goal-Oriented $=$ High Goal Orientation

$\mathrm{R}^{2}=.320$, Adjusted $\mathrm{R}^{2}=.304 ; F(12,506)=19.83, p<.001$

\begin{tabular}{l|c|c|c|c|c}
\hline High Apathy Orientation & $\mathrm{B}$ & $\mathrm{SE}$ & $\beta$ & $t$-value & $p$ value \\
\hline (Constant) & 1.536 & 0.645 & & 2.381 & 0.019 \\
Relationship fairness & 0.214 & 0.100 & 0.240 & 2.140 & 0.034 \\
Relationship stability & 0.064 & 0.094 & 0.078 & 0.677 & 0.500 \\
\hline Social relation etiquette & 0.038 & 0.082 & 0.046 & 0.466 & 0.642 \\
Oral etiquette & 0.003 & 0.042 & 0.007 & 0.082 & 0.935 \\
Commitment etiquette & 0.152 & 0.115 & 0.166 & 1.320 & 0.189 \\
Cultural sensitivity etiquette & 0.088 & 0.076 & 0.114 & 1.159 & 0.249 \\
Family networks (Guanxi) & -0.004 & 0.050 & -0.007 & -0.081 & 0.936 \\
Role & 0.010 & 0.130 & 0.006 & 0.075 & 0.940 \\
Business experience (years) & 0.038 & 0.066 & 0.051 & 0.576 & 0.566 \\
Gender & 0.093 & 0.106 & 0.073 & 0.880 & 0.381 \\
Age & -0.061 & 0.097 & -0.055 & -0.628 & 0.531 \\
Marital status & 0.311 & 0.149 & 0.165 & 2.086 & 0.039 \\
\hline
\end{tabular}

Dependent Variable: Relationship Performance

Selecting only cases for which Apathetic-Oriented = High Apathy

$\mathrm{R}^{2}=.349$, Adjusted $\mathrm{R}^{2}=.282 ; F(12,118)=5.26, p<.001$ 